\title{
The dichotomous structure of the warm conveyor belt
}

Article

Accepted Version

Martinez-Alvarado, O., Joos, H., Chagnon, J., Boettcher, M., Gray, S., Plant, R. S., Methven, J. and Wernli, H. (2013) The dichotomous structure of the warm conveyor belt. Quarterly Journal of the Royal Meteorological Society, 140 (683). pp. 1809-1824. ISSN 1477-870X doi: https://doi.org/10.1002/qj.2276 Available at https://centaur.reading.ac.uk/34519/

It is advisable to refer to the publisher's version if you intend to cite from the work. See Guidance on citing.

To link to this article DOI: http://dx.doi.org/10.1002/qj.2276

Publisher: Royal Meteorological Society

All outputs in CentAUR are protected by Intellectual Property Rights law, including copyright law. Copyright and IPR is retained by the creators or other copyright holders. Terms and conditions for use of this material are defined in the End User Agreement.

\section{www.reading.ac.uk/centaur}

\section{CentAUR}


Central Archive at the University of Reading

Reading's research outputs online 


\section{The dichotomous structure of the warm conveyor belt}

(Short title: The dichotomous structure of the warm conveyor belt)

Oscar Martínez-Alvarado ${ }^{1}$, H. Joos ${ }^{2}$, J. Chagnon ${ }^{1}$, M. Boettcher ${ }^{2}$, S. L. Gray ${ }^{1}$, R. S. Plant ${ }^{1}$, J. Methven ${ }^{1}$ and H. Wernli ${ }^{2}$

1 Department of Meteorology, University of Reading, United Kingdom 2 Institute for Atmospheric and Climate Science, ETH Zurich, Switzerland

October 11, 2013

Correspondence to:

Oscar Martínez-Alvarado

Department of Meteorology, University of Reading

Earley Gate, Reading, RG6 6BB, United Kingdom

E-mail: o.martinezalvarado@reading.ac.uk

Tel: +44 (0) 1183786374

Fax: +44 (0) 1183788905 


\section{Abstract}

The warm conveyor belt (WCB) of an extratropical cyclone generally splits into two branches. One branch (WCB1) turns anticyclonically into the downstream upper-level tropospheric ridge, while the second branch (WCB2) wraps cyclonically around the cyclone centre. Here, the WCB split in a typical North Atlantic cold-season cyclone is analysed using two numerical models: the Met Office Unified Model and the COSMO model. The WCB flow is defined using off-line trajectory analysis. The two models represent the WCB split consistently. The split occurs early in the evolution of the WCB with WCB1 experiencing maximum ascent at lower latitudes and with higher moisture content than WCB2. WCB1 ascends abruptly along the cold front where the resolved ascent rates are greatest and there is also line convection. In contrast, WCB2 remains at lower levels for longer before undergoing saturated large-scale ascent over the system's warm front. The greater moisture in WCB1 inflow results in greater net potential temperature change from latent heat release, which determines the final isentropic level of each branch. WCB1 also exhibits lower outflow potential vorticity values than WCB2.

Complementary diagnostics in the two models are utilised to study the influence of individual diabatic processes on the WCB. Total diabatic heating rates along the WCB branches are comparable in the two models with microphysical processes in the large-scale cloud schemes being the major contributor to this heating. However, the different convective parameterisation schemes used by the models cause significantly different contributions to the total heating.

These results have implications for studies on the influence of the WCB outflow in Rossby wave evolution and breaking. Key aspects are the net potential temperature change and the isentropic level of the outflow which together will influence the relative mass going into each WCB branch and the associated negative PV anomalies at the tropopause-level flow.

\section{Keywords}

Warm conveyor belt; extratropical cyclone; potential temperature; potential vorticity; diabatic processes 


\section{Introduction}

In the classical conveyor belt paradigm for extratropical cyclones (Browning, 1971; Harrold, 1973; Browning, 1990; Carlson, 1980; Schultz, 2001), ascent in the vicinity of the cold front is described in terms of a warm conveyor belt (WCB) which transports warm air from low levels and low latitudes both upwards and polewards. The ascent is viewed as being gradual and continuous, albeit sometimes enhanced by small-scale embedded convection that may be organized into clusters within the warm sector or as line convection along the cold front. A detailed description of the WCB flow emerged first from isentropic analyses (e.g. Namias, 1939) and later from satellite imagery from Young et al. (1987) and others (see Bader et al., 1995, for an overview). In this description the WCB splits into two parts. The primary part turns anticyclonically within the upper-level flow and emerges into a downstream tropopause ridge. The secondary part turns cyclonically around the cyclone centre within the lower to mid troposphere. These primary and secondary parts are often simply referred to as WCB1 and WCB2 (or W1 and W2 as in Browning and Roberts (1994) for example).

The conveyor belt paradigm was first introduced on the basis of isentropic analyses and inspection of radar and radiosonde observations and satellite imagery, but more recently it has also been shown to be fully consistent with more detailed trajectory analysis based on numerical simulations (e.g. Wernli and Davies, 1997; Eckhardt et al., 2004; Joos and Wernli, 2012; Martínez-Alvarado and Plant, 2013). Although there is an extensive literature on the airflows within a range of observed and simulated cyclones (see Schultz and Vaughan, 2011, and references therein), the questions of how and when the WCB splits has been relatively unexplored alongside questions of how the evolution of the air streams compares between the two branches. Diabatic processes enable transport upwards across isentropic surfaces to a level where either cyclonic or anticyclonic breaking is more prominent. The objective of this contribution is to investigate the local influence of diabatic processes on the splitting of a WCB. We aim to improve the understanding of the structure of the WCB1 and WCB2 flows and of the potential impact of their outflows on the tropopause structure. We will present evidence that aspects of the splitting may be related to details of the diabatic processes taking place along the WCB. Diabatic processes seem to be important in differentiating the two parts of the WCB not only as the WCB overruns the warm front, where the split is traditionally assumed 
to take place, but also at earlier times within the WCB air stream, along the trailing cold front.

The WCB split does not require moist diabatic processes to occur. Indeed, the split occurs even in dry baroclinic life-cycles, an example of which is given by branches $\mathrm{C}$ and D in Figure 1 of Thorncroft et al. (1993). In their interpretation these two branches are represented on the same isentropic surface, although they note that, in a moist scenario, latent heat release would enable cross-isentropic motion. The split is also an important feature in mediating the interactions of baroclinic waves with other physical mechanisms in the atmosphere. Again even in dry simulations, the existence of a distinct lower branch to the WCB is important in the interactions between baroclinic waves and an underlying turbulent boundary layer (e.g. Adamson et al., 2006; Plant and Belcher, 2007; Sinclair et al., 2010).

It is well established that the effect of moist processes on the evolution of baroclinic-wave life-cycles is more involved than a simple enhancement of the baroclinic instability growth rate due to latent heat release (Martin, 2006; Pavan et al., 1999; Boutle et al., 2010). Nonetheless there are long-standing debates on the role of moist processes within extratropical cyclones and especially on the question of whether latent heat release critically modifies the development of the large-scale circulation or whether it produces only localized modifications within large-scale circulations the structure of which is essentially dictated by the dry dynamics (e.g. Whitaker and Davis, 1994; Ahmadi-Givi et al., 2004; Bracegirdle and Gray, 2009; Davis et al., 1993; Stoelinga, 1996).

At least to some extent the relatively little attention devoted to the WCB split and the role of diabatic processes within it may be due to the lack of routinely available detailed diagnostics with which to address the issues. Very recent work by Joos and Wernli (2012) and Martínez-Alvarado and Plant (2013) has helped to rectify this difficulty by developing sets of diagnostics to integrate potential temperature tendencies from different model processes in a Lagrangian framework. We combine and expand on their approaches in the present article. Specifically Joos and Wernli (2012) have developed a suite of heating diagnostics for unpicking the various contributions to the microphysical tendencies, accumulated along trajectories, occurring in the COSMO (COnsortium for Small-scale MOdelling) model, while Martínez-Alvarado and Plant (2013) have developed a suite of heating diagnostics for unpicking the various contributions to diabatic heating from all of the separate parameterised processes, 
accumulated in the form of tracer fields, in the Met Office Unified Model (MetUM). The diagnostic methods are complementary, as we will demonstrate, with the MetUM diagnostics providing a comprehensive picture of the time-history of all parameterised processes and the COSMO model diagnostics providing a more detailed description of the diabatic heating caused by different microphysical processes during the formation of clouds. The effects of diabatic heating on the development of potential vorticity (PV) are also investigated. These novel diagnostics are put into their full context for the present aims and are suitably interpreted by also using trajectory calculations which allow the WCB and its split into WCB1 and WCB2 to be cleanly identified.

Our analysis is based on simulations of a case study with two different models, which are configured in as similar a way as possible and forced with the same input data. The case was chosen as a typical cold-season North Atlantic cyclone with clear WCB1 and WCB2 features readily apparent in the satellite imagery (for example see Figure 1 which is discussed further below). The case benefits from a research flight that enables direct comparison of the numerical simulations with a section of dropsonde observations as well as in-situ measurements that reveal the actual structure of the cold front. This data is valuable in allowing us to ensure not only that the two models are able to provide accurate simulations of the case in comparison with the available observations but also that the simulations are close enough together that the study of each can be used in a complementary fashion to provide additional information about the case.

We use the models in hindcast mode with each having its default numerical weather prediction settings for the most part, including its normal choice of parameterisations (see Section 2.1). We focus on the results of two simulations in the following. Other simulations were performed, however, to verify on some of the interpretations and possible sensitivities. Most notable for the presentation here is that each model was run with the Kain-Fritsch convective parameterisation scheme (Kain and Fritsch, 1990; Kain, 2004) as an alternative option. These simulations reveal to what extent differences in convective activity between the models are a function of the convection scheme per se and to what extent they are dependent on the behaviour of the large-scale microphysics parameterisation and the dynamical environment to which a convection parameterisation responds.

The remainder of this article is organized as follows. Section 2.1 describes the numeri- 
cal models used and their configuration for this study. The diagnostic methods used for the MetUM and the COSMO model are presented in Sections 2.2 and 2.3 respectively, while the trajectory computations are defined in Section 2.4. A synoptic analysis of the case is given in Section 3, including a validation of the models' performance against observational data. The two branches of the WCB are identified using trajectory calculations in Section 4 and differences in the diabatic heating along the two branches are noted. Such differences are investigated systematically in Section 5 and their effects on PV are considered in Section 5.2. A summary of the main results can be found in Section 6 alongside further discussion focusing on their wider implications.

\section{Methodology}

\section{$2.1 \quad$ Numerical models}

Two models have been used in this work: the MetUM (Davies et al., 2005) version 7.3 and the COSMO model (Steppeler et al., 2003).

The MetUM is a finite-difference model that solves the non-hydrostatic, deep-atmosphere dynamical equations with a semi-implicit, semi-Lagrangian integration scheme (Davies et al., 2005). The model uses Arakawa C staggering in the horizontal (Arakawa and Lamb, 1977) and is terrain-following in the vertical with a hybrid-height coordinate and Charney-Phillips staggering (Charney and Phillips, 1953). A rotated horizontal grid is used in the limited-area model (LAM) configuration, which has one-way nesting from the global model. The parameterisation of physical processes includes longwave and shortwave radiation (Edwards and Slingo, 1996), boundary layer mixing (Lock et al., 2000), convection (Gregory and Rowntree, 1990), and cloud microphysics and large-scale precipitation (Wilson and Ballard, 1999).

The COSMO model is also a non-hydrostatic, fully-compressible LAM. It also uses rotated Arakawa C staggering in the horizontal and a terrain-following, hybrid-height vertical coordinate, but this has Lorenz staggering (Lorenz, 1960). The physical parameterisations include sub-grid-scale turbulence (Mellor and Yamada, 1982), surface layer exchange (Louis, 1979), longwave and shortwave radiation (Ritter and Geleyn, 1989), convection (Tiedtke, 1989), and cloud microphysics (Doms et al., 2007). 


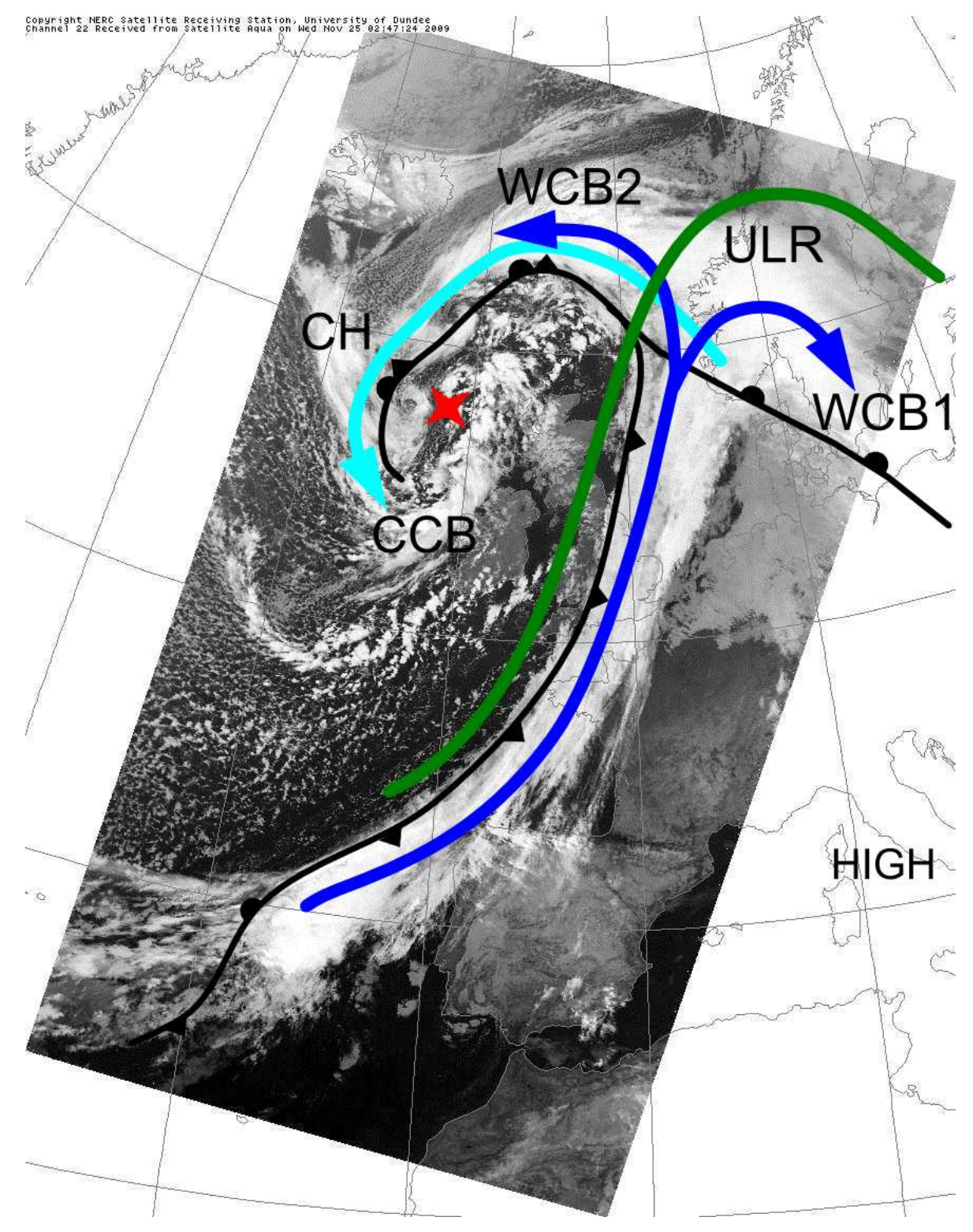

Figure 1: Infrared satellite image (MODIS channel 22) valid at 0247 UTC 25 November 2009 (Image courtesy of the NERC Satellite Receiving Station, Dundee University, Scotland, http://www.sat.dundee.ac.uk/). The frontal structure, the position of the low-pressure centre (red star) and the position of a centre of high mean sea level pressure (HIGH) are based on Met Office analysis valid at 0000 UTC 25 November 2009. The dark blue line indicates the approximate location of the WCB and its split into anticyclonic (WCB1) and cyclonic (WCB2) branches; the light blue line indicates the approximate location of the cold conveyor belt; the green line indicates the position of the upper-level ridge (ULR). The letters ' $\mathrm{CH}$ ' indicate the cloud head. 
The simulations have been performed on the same domain in both models. This domain covers nearly all of the North Atlantic and Europe, extending from eastern Canada, and including most of Greenland and the northern part of North Africa. The domain extends approximately from $25^{\circ} \mathrm{N}$ to $75^{\circ} \mathrm{N}$ in latitude and from $70^{\circ} \mathrm{W}$ to $60^{\circ} \mathrm{E}$ in longitude. The MetUM uses a horizontal grid spacing of $0.11^{\circ}(\sim 12 \mathrm{~km})$ and $820 \times 500$ grid points. There are 38 vertical levels with a lid at around $39 \mathrm{~km}$. The COSMO model uses a horizontal grid spacing of $0.125^{\circ}(\sim 14 \mathrm{~km})$ and has 40 vertical levels. The spacing of the vertical levels in the MetUM (COSMO model) is $\sim 60 \mathrm{~m}(\sim 70 \mathrm{~m})$ close to the surface and increases to $\sim 800 \mathrm{~m}(\sim 600 \mathrm{~m})$ at a height of $7 \mathrm{~km}$.

Both models have been initialised from the ECMWF operational analysis at 0600 UTC 23 November 2009. The MetUM has been run from these initial conditions in its global configuration to produce lateral boundary conditions to be used by the LAM simulation. The COSMO model, on the other hand, takes lateral boundary conditions directly from the ECMWF operational analysis interpolating these in time every hour. The MetUM was found to be more sensitive to the initialisation time than the COSMO model possibly due to its reliance on self-produced lateral boundary conditions. Therefore, the initialisation time was chosen as to minimise the differences between the ECMWF operational analysis and the simulations presented here. This issue is discussed further in Section 3. Both models have been run for 66 hours, including the trajectory computation periods (see Section 2.4).

\subsection{Tracers for potential temperature and moisture in the MetUM}

The tracer method for potential temperature $(\theta)$ and moisture variables (specific humidity $q$, cloud liquid content $q_{\mathrm{cl}}$, and cloud ice content $q_{\mathrm{cf}}$ ) consists of a series of tracers, each one accumulating the effect on the variables of interest $\left(\theta, q, q_{\mathrm{cl}}, q_{\mathrm{cf}}\right)$ of one specific parameterised process in the model. The method has been previously described in Martínez-Alvarado and Plant (2013). In that work the tracer method was applied to investigate the balance between parameterised and resolved convection in an extratropical cyclone. The method is similar to the partitioned PV integration developed by Stoelinga (1996) for the investigation of latent heat of condensation and surface friction in a case of intense cyclogenesis. It is also similar to the PV tracers used to study cross-tropopause transport (Gray, 2006), the PV of convective storms (Chagnon and Gray, 2009) and the diabatic modification of PV in extratropical 
cyclones (Chagnon et al., 2013). The tracer method is described as follows. Each variable $\phi$ is decomposed into a complete set of tracer components such that $\phi=\phi_{0}+\sum_{\mathrm{P}} \Delta \phi_{\mathrm{P}}$. Each tracer component $\Delta \phi_{\mathrm{P}}$ accumulates the changes in $\phi$ that can be attributed to the parameterised process $P$. $\theta$ is modified by (i) boundary layer, (ii) convection, (iii) cloud microphysics and (iv) short- and long-wave radiation, whereas the water vapour and cloud liquid water are modified by processes (i)-(iii) only. The remaining tracer component $\phi_{0}$ is used to transport the initial distribution of $\phi$ with the flow. By definition, this tracer is not modified by any parameterisation but it is, nevertheless, subject to advection (using the in-built semi-Lagrangian scheme including implicit numerical dissipation).

The decomposition of $q_{\mathrm{cl}}$ enables the separation of the boundary layer $\theta$ tracer into two sub-components which otherwise would be difficult to differentiate. These sub-components are the contribution due to surface fluxes and turbulent mixing $\Delta \theta_{\mathrm{BLmix}}$ and the contribution due to latent heat effects $\Delta \theta_{\mathrm{BLlh}}$, both restricted to changes in the boundary layer (although the tracer itself is not confined). Thus,

$$
\Delta \theta_{\mathrm{BLlh}}=\frac{L}{c_{p}} \frac{\Delta q_{\mathrm{cl}, \mathrm{BL}}}{\Pi}
$$

where $\Delta q_{\mathrm{cl}, \mathrm{BL}}$ is the change in $q_{\mathrm{cl}}$ due to the boundary layer parameterisation, $L$ is the latent heat of condensation, $c_{p}$ is the specific heat of dry air at constant pressure and $\Pi=\left(\frac{p}{p_{0}}\right)^{\frac{R}{c_{p}}}$ is the Exner function, where $p$ is pressure, $p_{0}=1000 \mathrm{hPa}$ is a reference pressure and $R$ is the gas constant for dry air. The implicit assumption in this calculation is that water vapour is all being transformed into liquid water (either cloud or rain). This assumption is largely valid in the boundary layer but there will be a small error due to ice effects. The contribution due to surface fluxes and turbulent mixing is then computed as

$$
\Delta \theta_{\mathrm{BLmix}}=\Delta \theta_{\mathrm{BL}}-\Delta \theta_{\mathrm{BLlh}}
$$

Latent heat effects in the boundary layer are in fact part of the modification of $\theta$ due to cloud microphysics as they are caused by the same part of the model code in two different calls (inside and outside the boundary layer parameterisation). Therefore, from this point we shall refer to 
the contribution of cloud microphysics as the sum

$$
\Delta \theta_{\mathrm{mp}}=\Delta \theta_{\mathrm{mp}, \text { outBL }}+\Delta \theta_{\mathrm{BLlh}}
$$

where $\Delta \theta_{\mathrm{mp} \text {,outBL }}$ is the tracer accumulating the heating associated with the cloud microphysics parameterisation call outside of the boundary layer code.

\subsection{Diabatic heating rates in the COSMO model}

The cloud microphysics parameterisation scheme in the COSMO model includes water vapour, cloud water, cloud ice, rain and snow as prognostic variables. When clouds form, latent heat is released due to the transfer of mass between the different hydrometeor species. These diabatic heating rates (DHR) are calculated for all microphysical conversion processes within the model and the instantaneous values are stored at every model output (every hour in this study). The total DHR caused by microphysical processes is then given by the sum over all single processes. In the case study presented here, the DHR caused by condensation/evaporation (TCE), depositional growth of ice (TIDEP), depositional growth of snow (TSDEP), melting of snow (TSMELT), evaporation of rain (TEV) and convective heating (TCONV) are the most important heating/cooling processes. For a detailed description of these processes and a complete list of all microphysical processes see Joos and Wernli (2012) and for a complete description of the COSMO model microphysics see Doms et al. (2007).

Potential vorticity is modified by these diabatic processes (e.g. Hoskins et al., 1985). The main effect of DHR on the PV evolution in a WCB is the enhancement of PV below the maximum of the DHR and the depletion of PV above (Wernli, 1997). For each microphysical heating rate diagnostic, we also calculate and record the corresponding diabatic change in PV (DPVR) according to

$$
D P V R=\frac{D}{D t} P V=\frac{1}{\rho} \vec{\eta} \cdot \vec{\nabla} D H R
$$

where $D / D t$ denotes the material derivative and $\vec{\eta}$ the absolute vorticity vector. Changes in PV due to frictional mixing processes are not accounted for by this method. The total change in PV due to microphysics is given by the sum over all individual DPVRs. 


\subsection{Trajectory analysis}

Model-derived velocity components from both models were used to calculate offline trajectories. Trajectories in the COSMO model were calculated with the trajectory tool LAGRANTO (Wernli and Davies, 1997). For the MetUM, the trajectory calculation method described in Wernli and Davies (1997) was adapted to compute trajectories using MetUM output directly on the MetUM grid (described in Section 2.1). To investigate the WCB associated with the cyclone in this case study, forward trajectories were initialised from every grid point around the warm sector of the cyclone below a height of $1500 \mathrm{~m}$ at 1500 UTC, 1800 UTC and 2100 UTC on 23 November 2009 (i.e. 9, 12 and 15 hours after the start of the simulation). Only trajectories exhibiting ascent greater than $600 \mathrm{hPa}$ in $48 \mathrm{~h}$ were selected. It has been shown in several studies (e.g. Wernli and Davies, 1997; Eckhardt et al., 2004) that this selection criterion is sensible to select WCB trajectories if the ascent occurs in the vicinity of a cyclone. The three sets of trajectories were analyzed separately and yielded similar results irrespective of the initialization time. For the presentation here, we therefore show results only for the trajectories initialised at 1800 UTC 23 November 2009.

To filter out trajectories belonging to a second, short-lived low pressure system located to the south of the system of interest, an additional criterion was applied to the bundle of trajectories. Specifically, only trajectories that were located to the north of $45^{\circ} \mathrm{N}$ at least once within their 48-hour ascent were retained. This criterion removes those trajectories that start close to the southern low pressure system. Once trajectories were computed and selected, $p$, $q, \theta$ and PV were interpolated onto the trajectories in both models. Additionally, PV- and $\theta$-tracers were interpolated to MetUM trajectories and DHRs and DPVRs were interpolated to COSMO model trajectories. In the following sections, variables along trajectories are presented in terms of percentile curves. These curves are computed from the distribution belonging to the particular variable displayed at constant values of the independent variable (this being either time or pressure).

\subsection{Trajectory validity}

Unlike reality, in which length scales form a continuum, numerical models have a clear albeit artificial separation between grid- and sub-grid-scale processes. Mass flux convection schemes, 
like those used in the MetUM and the COSMO model, are designed so that the area-averaged vertical velocity (area-weighted updrafts, downdrafts and environment) equals the resolved vertical velocity. As such, mass flux convection schemes do not directly impact the vertical velocity at the grid-scale. However, they do have an indirect effect on vertical velocity by modifying the vertical profiles of temperature and moisture.

The methods described in this article are designed to work at the grid-scale resolution of the models. It is at that resolution that they are consistent in terms of the grid-scale effects of each parameterisation scheme (including convection) and in terms of the advection of these effects due to the grid-scale wind components. Our trajectory calculations are valid at the model grid scale and represent the motion of the centroids of air (macro) parcels with the model-resolved winds; they do not represent the motion of air (micro) parcels at sub-grid scales.

\section{Synoptic overview of case-study}

During the period 23 to 25 November 2009, an extratropical cyclone formed in the North Atlantic and moved eastward across the British Isles and Western Europe. The surface low, with a central pressure that fell below $960 \mathrm{hPa}$ on 25 November, amplified in concert with an upper-level trough. An overview of the synoptic evolution of this system is presented in this section.

A sequence of surface analyses from 23-25 November 2009 is shown in Figure 2. This period spans the phases of development of the primary low, including initial formation, amplification, and maturity. On 23 November 2009 (Figure 2a) a mature barotropic low was situated north of Scotland. This system, which is not the focus of our WCB analysis, moved northward and eastward in the subsequent two days. An east-west oriented baroclinic zone extended across the North Atlantic behind this mature low. By 0000 UTC on the 24th (Figure 2c) a surface cyclone had formed along the baroclinic zone in the North Atlantic. The primary low would wrap up and become occluded by 0000 UTC on 25th November (Figure 2e). The cold front and WCB cloud band moved across the UK during the afternoon on the 25th November. The deepening

of the surface cyclone and formation of the WCB was accompanied by an amplification of the upper-level trough. Figure 2 (right column) presents the potential vorticity (PV) on the $315 \mathrm{~K}$ isentropic surface. By 0000 UTC on 25 November (Figure 2f) the eastern edge of the 
primary upper-level trough was located over the Irish Sea. The downstream ridge extended far to the north over Scandinavia and a downstream trough had elongated far to the south over the eastern Mediterranean.

When the system had reached maturity, a south-to-north oriented cloud band running along the surface cold front was evident in the composite satellite imagery (Figure 3a). The cloud band split into two segments at its northern extremity, one turning cyclonically (westward) and one turning anticyclonically (eastward). The cloud tops within the anticyclonically-turning branch extended to higher altitudes than in the cyclonically-turning branch. A distinct shadow was cast by these higher cloud tops immediately to the west of the cloud band edge associated with the anticyclonically-turning branch. The radar rainfall rate composite (Figure 3b) indicates that there was heavy rain along the cold front within the WCB cloud band at 2100 UTC 24 November 2009. Precipitation rate was strongest at the leading edge of the cold front which was divided in segments along the front, a common pattern for line convection as described by Hobbs and Biswas (1979) (This feature was well represented by the models and will be discussed in more detail later). There was also heavy rain in a prominent band behind (west of) the leading edge of the cold front.

The cold front associated with this system was the focus of a research flight conducted on 24 November 2009 (Knippertz et al., 2010). The FAAM (Facility for Airborne Atmospheric Measurements) BAe-146 launched 7 dropsondes across the front between 1700 and 1800 UTC south of Ireland at approximately $51^{\circ} \mathrm{N}$ (approximately $900 \mathrm{~km}$ upstream along the WCB from the frontal triple point; for further detail about the flight track see Knippertz et al. (2010)). A comparison of the observed frontal structure in the dropsonde section with the simulated structure in the MetUM is presented in Figure 4. The intersection of WCB trajectories (see Section 4) is also depicted in the model sections in Figure 4(b,d). The comparison of the simulated and observed cross-frontal sections confirms that the general characteristics of the front (e.g. frontal slope, change in horizontal winds and equivalent potential temperature $\left(\theta_{e}\right)$ across the frontal interface) were simulated accurately. The surface front is located slightly farther to the west in the model; in-situ measurements across the front at low levels $(1000 \mathrm{ft}=$ $305 \mathrm{~m}$ ) during the FAAM research flight show that the displacement was only $100 \mathrm{~km}$, which is a small phase error for a 35-hour forecast. The horizontal gradient across the frontal interface 
appears sharper in the model section than in the dropsonde observations. However, these observations are limited by the spacing of the 7 dropsondes distributed across 6 degrees of longitude. Examination of in-situ measurements across the front at $1000 \mathrm{ft}$ reveals a drop of $14 \mathrm{~m} \mathrm{~s}^{-1}$ in meridional wind over just $600 \mathrm{~m}$, flying from east to west, equivalent to a horizontal shear of $0.02 \mathrm{~s}^{-1}$. The $600-\mathrm{m}$ frontal width is supported by measurements of other variables such as vertical wind and ozone. Therefore, the front is so tight that it cannot be resolved by the grid spacing employed in the simulation presented here and is also 100 times narrower than the spacing between the dropsondes. This comparison against observations confirms that the simulation provides an accurate representation of the frontal structure. Furthermore, the section indicates that the WCB trajectories at this location (about half-way between the southernmost and northernmost extremities of the front) was split into two bundles: one which had already ascended above the surface front and was characterized by high $\theta_{e}$ values, and one that was primarily located along the surface front and had not yet ascended. The split between these WCB trajectories will be analysed in detail in Section 4.

Figure 5a shows mean sea level pressure (MSLP) and the 2-PVU isoline $\left(1 \mathrm{PVU}=10^{-6} \mathrm{~m}^{2} \mathrm{~s}^{-1} \mathrm{~K} \mathrm{~kg}^{-1}\right)$ on the 315-K isentropic surface according to the ECMWF operational analysis at 1800 UTC 25 November, which is the time at the end of the trajectory analysis. Figures $5(\mathrm{~b}, \mathrm{c})$ show the corresponding forecasts $(\mathrm{T}+60)$ from the MetUM and the COSMO model simulations, respectively. The cyclone appears approximately $4 \mathrm{hPa}$ deeper in the forecasts than in the operational analysis and there is an error in the location of the cyclone low-pressure centre of approximately $200 \mathrm{~km}$. Moreover, the upper-level ridge on the 315-K isentropic surface appears more wrappedup in the forecasts than in the analysis. This feature is especially noticeable in the MetUM simulation (Figure 5b). However, considering the long lead time of these forecasts (60 hours), these differences are not surprising and the model results can be considered as a plausible and an acceptably accurate representation of the state of the atmosphere for the purposes of this study.

In summary, the extratropical cyclone that occurred between 23-25 November 2009 was chosen as an example of a typical cold-season cyclone in the North Atlantic in which a distinct WCB formed. Satellite imagery provides clear evidence for a WCB cloud band along the surface cold front extending from south to north, and then splitting into cyclonic and anticyclonic 
branches at its northern extremity. Precipitation was heavy and continuous along the length of the cold front during the period 23-25 November 2009. As such, this is an ideal case for examining diabatic heating in a $\mathrm{WCB}$ as well as the mechanisms driving its split into two separate air streams. The upper-level trough associated with the primary low amplified in concert with the surface low. The downstream ridge and downstream trough also amplified during this period.

\section{The two branches of the WCB}

Figure 3a clearly shows a difference in cloud-top height between WCB1 and WCB2 in satellite imagery. Although the WCB split is only evident in satellite imagery close to the cyclone centre after the original WCB has apparently risen above the surface warm front, we shall show that the split actually starts further south and along the cold front. To define the split of the WCB into two branches the value of $\theta$, acting as a vertical-coordinate variable, at the final trajectory point was chosen as separating variable. Thus, WCB1 trajectories were defined as those trajectories for which $\theta\left(t_{\text {traj }}=48 \mathrm{~h}\right)>307.5 \mathrm{~K}$ whereas WCB2 trajectories were defined as those for which $\theta\left(t_{\text {traj }}=48 \mathrm{~h}\right)<307.5 \mathrm{~K}$, where $t_{\text {traj }}$ indicates trajectory time from 1800 UTC 23 November 2009.

The resulting trajectory bundles representing WCB1 and WCB2 are shown in Figure 6. In the COSMO model, WCB1 consists of 32240 trajectories and WCB2 of 21014 trajectories. In the MetUM, WCB1 consists of 33466 trajectories and WCB2 of 3322 trajectories. A complete separation of the trajectories into a cyclonically and an anticyclonically turning branch based on their final $\theta$ value is not possible in either model. However, the majority of trajectories contained in WCB1 do belong to the anticyclonically turning branch. Furthermore, the presence of a few cyclonic trajectories in WCB1 does not meaningfully change the statistical properties of this air stream. This statement has been tested by separating the branches with different final $\theta$ values.

The trajectories in Figure 6 are coloured by pressure. Figure 6 also shows MSLP at the trajectory start time (1800 UTC 23 November) and the 315-K 2-PVU isoline at the trajectory end time (1800 UTC 25 November). Every trajectory starts in a region to the west of $10^{\circ} \mathrm{W}$ and to the south of $50^{\circ} \mathrm{N}$ and the vast majority of them start to the east of the cold front in what 
was the system's warm sector at 1800 UTC 23 November 2009. There is no obvious difference between the starting regions of WCB1 and WCB2. This has been tested further by attempting the separation of branches by the values of different variables such as specific humidity, potential temperature and equivalent potential temperature at the trajectory starting time. Even though the branches exhibit some differences in their initial moisture content $\left(7.6<q<10.3\left[\mathrm{~g} \mathrm{~kg}^{-1}\right]\right.$ in WCB1 and $7.1<q<7.7\left[\mathrm{~g} \mathrm{~kg}^{-1}\right]$ in WCB2 in the MetUM), none of these attempts produced as clean a separation as the one obtained by using $\theta$ at the final trajectory time.

WCB1 shows a pattern of rapid ascent which starts to the south of the cyclone centre so that most of the trajectories constituting this branch are at low pressures for most of their evolution (Figure 6(a,c)). These trajectories continue to travel to the east bordering the upperlevel tropospheric ridge, as marked by the 315-K 2-PVU isoline. This behaviour is in good agreement with the findings by Eckhardt et al. (2004) regarding the final position of WCB trajectories after 48 hours of ascent. WCB2, on the other hand, remains at high pressures for longer, starting its ascent further northeast, closer to the cyclone centre and to the warm front (Figure 6(b,d)).

To highlight the differences between the two branches, the time evolution of pressure, latitude, specific humidity and potential temperature is shown in Figure 7, where time zero is defined as the time of maximum vertical velocity $\left(w_{\max }\right)$ for each trajectory. Air parcels in WCB1 stay relatively close to the surface and start to rise rapidly around the time of $w_{\max }$ (Figure 7a). In contrast, WCB2 air parcels start to ascend more slowly and earlier, in general showing a less abrupt ascent than WCB1 (Figure 7b). This effect is perhaps more noticeable in the MetUM than in the COSMO model.

The two branches are already horizontally separated at the time of $w_{\max }$. In fact, even 24 hours before this occurs there is a clear latitudinal separation between branches (Figure 7(c,d)). WCB1 trajectories between the 25th and 75th percentiles undergo strongest ascent between $40^{\circ} \mathrm{N}$ and $47^{\circ} \mathrm{N}$ in both models (Figure 7c). These latitudes correspond to the latitudes where vertical velocity along the cold front is maximum, as shown in Figure 8 for the MetUM (similar structure can be found in the COSMO model). Figure 8 shows regions of maximum vertical velocity arranged in a wave-like pattern along the cold front, in which a segment of enhanced ascent is followed by a segment of neutral ascent. These segments are related to the precipitating 
segments apparent in radar imagery (see Figure $3 \mathrm{~b}$ ). This pattern is more noticeable to the south of $51^{\circ} \mathrm{N}$, which is where WCB1 trajectories are subject to strongest ascent. In contrast, WCB2 trajectories between the second and third quartiles undergo strongest ascent between $50^{\circ} \mathrm{N}$ and $65^{\circ} \mathrm{N}$ in both models (Figure $7 \mathrm{~d}$ ). These latitudes are more consistent with largescale ascent near the cyclone centre where the low-level jet component of the WCB encounters the system's warm front, rising over it along a surface of constant $\theta_{e}(c f$. Figure 8$)$ in a similar manner as the 'trowal airstream' described by Martin (1998) and Martin (1999). This is consistent with the situation depicted by Figures 4(b,d), which show the vertical separation between the two branches. WCB1 trajectories intersecting that section (black circles) are already located at upper levels after ascending vertically and then slantwise over the cold anafront. WCB2 trajectories (white circles), on the other hand, are located closer to the surface. This is also consistent with the ascent pattern previously described while discussing Figure 6.

As well as experiencing strong ascent at lower latitudes, WCB1 trajectories are characterised by a much higher specific humidity at the time of $w_{\max }$ than WCB2 trajectories (Figure $\left.7(\mathrm{e}, \mathrm{f})\right)$. Trajectories in WCB1 reveal $q$ values around $7 \mathrm{~g} \mathrm{~kg}^{-1}$ with a tendency to increase slightly, briefly before $w_{\max }$ occurs (Figure $7 \mathrm{e}$ ). Around the time of the maximum vertical velocity, $q$ strongly decreases to $\sim 1 \mathrm{~g} \mathrm{~kg}^{-1}$ in only 10 hours. In contrast, in WCB2 $q$ starts to decrease already 10 hours before the time of strongest ascent and decreases more slowly to low values in the upper troposphere (Figure $7 \mathrm{f}$ ). These results indicate that the larger amount of moisture available to WCB1 parcels provided this branch with a larger source of energy through latent heat release. Indeed, the change in potential temperature is slightly larger in WCB1 (Figure 7g) than in WCB2 (Figure 7h).

As well as differences between the branches, there are differences between the two models, especially in WCB1. While the median change in potential temperature in WCB2 is $\sim 18 \mathrm{~K}$ in both models, the median change in potential temperature in WCB1 is $\sim 26 \mathrm{~K}$ in the MetUM and $\sim 22 \mathrm{~K}$ in the COSMO model. The enhanced heating in WCB1 trajectories causes this branch to reach higher isentropic surfaces, turn anticyclonically and contribute to the ridge formation downstream of the cyclone. The motion of both branches is largely moist-adiabatic: WCB1 trajectories between the 25 th and 75 th percentiles remain within a $10-\mathrm{K} \theta_{e}$ band throughout their 
48-h development whereas the equivalent WCB2 trajectories remain within a more restrictive 5-K $\theta_{e}$ band throughout their 48-h development. The change in specific humidity along WCB1 trajectories described in the previous paragraph and the fact that $\theta_{e}$ is being approximately conserved indicates that the ascent observed in WCB1 trajectories is caused by latent heat being rapidly released to generate strong cross-isentropic motion. The more gradual decrease in specific humidity along WCB2 trajectories while approximately conserving $\theta_{e}$ also explains the smoother cross-isentropic ascent of these trajectories. Section 5 is devoted to the discussion of the diabatic heating mechanisms in detail.

\section{$5 \quad$ Heating and PV modification in the WCB}

\subsection{Detailed analysis of heating rates}

Figure 9 shows total DHR along WCB1 and WCB2 as a function of pressure in the MetUM. In WCB1 the median of the total DHR increases from small values $\left(D \theta / D t<1 \mathrm{~K} \mathrm{~h}^{-1}\right)$ near the surface $(p>950 \mathrm{hPa})$ to a peak of $5 \mathrm{~K} \mathrm{~h}^{-1}$ at around $800 \mathrm{hPa}$. From this point the median decreases monotonically until it reaches negligible values around $350 \mathrm{hPa}$. The full ensemble follows a broadly similar behaviour although the ensemble spread is such that some trajectories reach total DHR values larger than $10 \mathrm{~K} \mathrm{~h}^{-1}$ around $700 \mathrm{hPa}$. In WCB2 the median of the total DHR exhibits two peaks. The first peak, slightly above $2 \mathrm{~K} \mathrm{~h}^{-1}$, is located around 820 $\mathrm{hPa}$; the second peak, around $1.75 \mathrm{~K} \mathrm{~h}^{-1}$, is located around $600 \mathrm{hPa}$. At near-surface levels $(p>950 \mathrm{hPa})$ many trajectories exhibit cooling, mainly due to evaporation of precipitation falling from upper levels, as will be shown below. The results obtained with the COSMO model (not shown) are consistent with these results, even though they account only for contributions from cloud microphysics.

The use of $\theta$-tracers in the MetUM allows the decomposition of the total DHR in terms of contributions from individual parameterised diabatic processes. Figure 10a shows the most important contributions to total DHR in both branches and according to $\theta$-tracers in the MetUM. The first most important contribution is due to cloud microphysics. The median of this contribution reaches its global maximum $\left(D \Delta \theta_{\mathrm{mp}} / D t \simeq 2.5 \mathrm{~K} \mathrm{~h}^{-1}\right)$ around $800 \mathrm{hPa}$ and a secondary maximum $\left(D \Delta \theta_{\mathrm{mp}} / D t \simeq 2 \mathrm{~K} \mathrm{~h}^{-1}\right)$ around $600 \mathrm{hPa}$ (Figure 10a, black solid 
line). WCB2 trajectories show a similar pattern of heating due to cloud microphysics, but with lower values throughout the pressure layer (Figure 10a, black dashed line): a global maximum $\left(D \Delta \theta_{\mathrm{mp}} / D t \simeq 2 \mathrm{~K} \mathrm{~h}^{-1}\right)$ around $800 \mathrm{hPa}$ and a secondary maximum $\left(D \Delta \theta_{\mathrm{mp}} / D t \simeq 1.5 \mathrm{~K} \mathrm{~h}^{-1}\right)$ around $625 \mathrm{hPa}$.

The second most important contribution to total DHR in the MetUM is due to the convection parameterisation. This contribution is concentrated primarily at lower levels $(p<600 \mathrm{hPa})$ with a single maximum $\left(D \Delta \theta_{\text {conv }} / D t \simeq 1.5 \mathrm{~K} \mathrm{~h}^{-1}\right.$ ) around $800 \mathrm{hPa}$ (Figure 10a, blue solid line). Unlike $D \Delta \theta_{\mathrm{mp}} / D t$ which displays a similar (albeit of different intensity) behaviour in both branches, $D \Delta \theta_{\text {conv }} / D t$ displays very different behaviour. In WCB2 a single unambiguous maximum $\left(D \Delta \theta_{\text {conv }} / D t \simeq 0.5 \mathrm{~K} \mathrm{~h}^{-1}\right)$ is found at $870 \mathrm{hPa}$ and negligible contribution at upper levels ( $p<800 \mathrm{hPa}$; Figure 10a, blue dashed line). Thus, the overall contribution due to parameterised convection in WCB1 is stronger than in WCB2 in the MetUM.

The DHR analysis in the COSMO model also shows a difference in heating between WCB1 and WCB2 consistent with the enhanced heating observed in WCB1 in comparison with WCB2. However, in this case the contribution from microphysical processes is more important than that from convection by one order of magnitude in both branches (Figure 10b). It is important to note that even though the DHRs are different in the two models, the time integral of DHRs through the WCB is similar (to give the increase in $\theta$ shown in Figure $7(\mathrm{~g}, \mathrm{~h})$ ). In WCB1 the contribution due to microphysical processes exhibits a peak in the ensemble-median of $2.20 \mathrm{~K} \mathrm{~h}^{-1}$ around $875 \mathrm{hPa}$ and a secondary maximum of $1.75 \mathrm{~K} \mathrm{~h}^{-1}$ around $670 \mathrm{hPa}$ (Figure 10b, black solid line). In WCB2 this contribution reaches $1.60 \mathrm{~K} \mathrm{~h}^{-1}$ around 850 $\mathrm{hPa}$ and remains around that value up to $600 \mathrm{hPa}$. Above this level the contribution due to microphysical processes steadily decreases reaching zero around $350 \mathrm{hPa}$ (Figure 10b, black dashed line). On the other hand, the contribution due to convection may be significant for some individual trajectories but remains low in the median (DHR $<0.3 \mathrm{~K} \mathrm{~h}^{-1}$ ) throughout the pressure layer $(300<p<1000[\mathrm{hPa}])$ in both branches (Figure 10b, blue solid and dashed lines). This contribution only slightly enhances the median DHR in the lower troposphere, in clear contrast with the MetUM results.

With the DHR analysis implemented in the COSMO model it is possible to investigate in further detail the relative contributions of the different microphysical processes to the total 
latent heating during cloud formation along the WCB trajectories (Figure 11). The maximum in the total DHR in WCB1 around $875 \mathrm{hPa}$ (Figure 10b) is caused by condensation of water vapour and the formation of a liquid cloud (Figure 11, purple solid line). This contribution peaks around $875 \mathrm{hPa}$ with a value of $2.20 \mathrm{~K} \mathrm{~h}^{-1}$ and extends from the surface to the midtroposphere $(550<p<1000[\mathrm{hPa}])$. While WCB1 parcels travel through the lower troposphere, they are also subject to slight cooling, mainly due to evaporation of rain below $900 \mathrm{hPa}$ and melting of snow around $750 \mathrm{hPa}$ (Figure 11, solid blue and green lines, respectively). The small amount of cooling found is consistent with the trajectory selection criteria, which only selects trajectories that ascend the most from the warm sector. However, due to sedimentation of rain and snow, some of the falling hydrometeors cross the path of the ascending trajectories while evaporating or melting, thus reducing the overall heating. When WCB1 parcels rise and reach the freezing level (around $700 \mathrm{hPa}$ ), ice phase processes become important. The second maximum in the median of the total DHR is largely caused by the depositional growth of snow and ice (Figure 11, solid yellow and red lines, respectively). This direct transfer of water vapour to the solid phase releases an important amount of latent heat above $700 \mathrm{hPa}$. There is also a contribution from the freezing of liquid cloud droplets. However, this contribution is only of secondary importance compared to those shown in Figure 11.

A similar partitioning of microphysical contributions is found in WCB2 (Figure 11, dashed lines). As in WCB1, the largest contribution at lower levels (below $600 \mathrm{hPa}$ ) is the condensation of water vapour for the formation of liquid cloud (Figure 11, dashed purple line). However, this peaks at slightly higher levels (around $800 \mathrm{hPa}$ ) than it does in WCB1, and its intensity is lower throughout (maximum of $1.80 \mathrm{~K} \mathrm{~h}^{-1}$ in WCB2 compared to $2.20 \mathrm{~K} \mathrm{~h}^{-1}$ in WCB1). Furthermore, evaporation of rain and melting of snow (Figure 11, dashed blue and green lines, respectively) produce cooling effects of slightly larger intensity than in WCB1. Therefore, the cooling to heating ratio is larger in WCB2 than in WCB1 at these levels so that the cooling effects are more noticeable in WCB2. Around $800 \mathrm{hPa}$, where the DHR from condensation peaks, the net DHR is around $1.50 \mathrm{~K} \mathrm{~h}^{-1}$, while at near-surface levels (below $950 \mathrm{hPa}$ ), a clear net cooling effect can be observed (Figure 10b). Around the freezing level, both the contributions from depositional growth of snow and ice in WCB2 (Figure 11, dashed yellow and red lines, respectively) peak below the corresponding contributions in WCB1. The peak in the contribu- 
tion due to depositional growth of snow is slightly smaller than in WCB1, whereas the peak in the contribution due to depositional growth of ice is slightly larger. From this description it is clear that, unlike in the MetUM, the difference between WCB1 and WCB2 in the COSMO model is due to the extent and intensity of the contribution due to the condensation of water vapour to cloud liquid rather than in the contribution from the convection parameterisation.

Additional simulations were performed with both the MetUM and the COSMO model using a different convection scheme to determine the cause of the different contributions to heating from convection in the two models. In these simulations, the Gregory-Rowntree (Gregory and Rowntree, 1990) and the Tiedtke (Tiedtke, 1989) convection parameterisation schemes normally used in the MetUM and COSMO, respectively, were replaced by the KainFritsch convection parameterisation scheme (Kain and Fritsch, 1990; Kain, 2004). The results from these simulations were similar to each other regarding both the spatial distribution of total precipitation and the way in which the total precipitation was split into convective and large-scale precipitation (not shown). Specifically, with the Kain-Fritsch scheme both models produced maxima in the total precipitation rate between $8 \mathrm{~mm} \mathrm{~h}^{-1}$ and $32 \mathrm{~mm} \mathrm{~h}^{-1}$ concentrated along a line of convection on the eastern flank of the cold front and between $4 \mathrm{~mm} \mathrm{~h}^{-1}$ and $16 \mathrm{~mm} \mathrm{~h}^{-1}$ to the northeast of the low-pressure centre. These numbers were also similar to those obtained with the models' standard convection parameterisation schemes. The precipitation from the Kain-Fritsch parameterisation was concentrated behind and in the southern section of the cold front (e.g. at 0600 UTC 24 November 2009 both models showed parameterised convective activity to the south of $40^{\circ} \mathrm{N}$ ). These results confirm that the differences in the simulated heating in the standard model configurations are mainly due to differences in their standard convection parameterisation schemes.

The differences between the MetUM and the COSMO model can be interpreted by recalling that in numerical models the distinction between parameterised and resolved convection arises from whether the convection parameterisation scheme triggers or not. This does not exactly map onto whether convection processes are occurring in the model but establishes a clear separation nevertheless. In the actual atmosphere there is no clear separation between processes to allow an unambiguous distinction. Both models show that WCB1 parcels contain more moisture and are located more to the southwest than WCB2 parcels at the time of maximum 
Table 1: Total change in $\theta(\Delta \theta)$ and PV $(\Delta \mathrm{PV})$ along the full length of trajectories (from 1800 UTC 23 November to 1800 UTC 25 November) for each WCB branch in each model.

\begin{tabular}{c|ccc|ccc||ccc|ccc} 
& \multicolumn{6}{|c||}{ WCB1 } & \multicolumn{6}{c}{ WCB2 } \\
\hline & \multicolumn{3}{|c|}{$\Delta \theta(\mathrm{K})$} & \multicolumn{3}{|c||}{$\Delta \mathrm{PV}(\mathrm{PVU})$} & \multicolumn{3}{c||}{$\Delta \theta(\mathrm{K})$} & \multicolumn{3}{c}{$\Delta \mathrm{PV}(\mathrm{PVU})$} \\
\hline Percentile & $25 \%$ & $50 \%$ & $75 \%$ & $25 \%$ & $50 \%$ & $75 \%$ & $25 \%$ & $50 \%$ & $75 \%$ & $25 \%$ & $50 \%$ & $75 \%$ \\
\hline MetUM & 22.6 & 25.6 & 27.8 & -0.024 & 0.103 & 0.298 & 17.5 & 18.6 & 19.3 & 0.188 & 0.713 & 2.60 \\
COSMO & 19.5 & 22.3 & 25.3 & -0.073 & 0.102 & 0.377 & 16.4 & 17.6 & 18.8 & 0.043 & 0.270 & 0.75
\end{tabular}

ascent. Furthermore, the WCB1 parcels' location is characterised by strong frontal lifting along the cold front in both models. The latent heat release in the form of forced convection produced when the WCB1 moist air is lifted provides the heating required for the stronger crossisentropic motion exhibited by this WCB branch relative to WCB2. The partitioning between parameterised and resolved convection between the models is different, with the convection scheme in the MetUM releasing part of the convective instability which in the COSMO model is released explicitly and so appears in the cloud microphysics scheme. The more active convection scheme in the MetUM explains the difference of about $4 \mathrm{~K}$ in total heating between the MetUM and the COSMO model. Thus, despite differences in how the standard model configurations partition convection, there is no fundamental conflict in how the differences between WCB1 and WCB2 arise.

\subsection{Diabatic PV modification}

The geographical distribution and diabatic modification of air parcels in the WCB outflow are highlighted in Figure 12 for WCB1 and in Figure 13 for WCB2. These figures show the location of WCB parcels close to the 315-K (Figure 12) and 305-K (Figure 13) isentropic surfaces at 18 UTC 25 November 2009, as an indication of the trajectories intersecting this surface. Parcels are coloured by total heating during their 48 hours ascent $(\Delta \theta)$ and final PV values (corresponding to the time shown). To complement this data, Table 1 summarizes the changes in $\theta$ and PV during the 48-hour trajectory time span for the two WCB branches and for both the MetUM and the COSMO model.

In both models, most of the trajectories that originated in WCB1 have been discharged from the WCB outflow by this time and deposited along the eastern edge of the downstream ridge (Figure 12). A smaller proportion of parcels remain to the west within WCB1, downstream of the upper-level trough. The result is a wishbone pattern of parcels distributed along the 
edge of the upper-level trough and ridge. In contrast to WCB1, most of the parcels discharged from WCB2 are wrapped cyclonically around the northwest quadrant of the cyclone centre (Figure 13). In the MetUM (Figure 13a,c) the parcels are exclusively located in this northwest quadrant, whereas in the COSMO model (Figure 13b,d) some of the parcels lag behind and are located to the northeast of the cyclone centre.

The WCB1 parcels experienced significant warming in most places in both the MetUM and the COSMO model after 48 hours (see Figure 12a,b) However the warming is slightly larger in the MetUM than in the COSMO model with a median difference between models of about $3 \mathrm{~K}$ and interquartile range of $22.6 \mathrm{~K}$ to $27.8 \mathrm{~K}$ in the MetUM and 19.5 to $25.3 \mathrm{~K}$ in the COSMO model (see Table 1).

The WCB1 parcels are also characterized by low values of PV, typically less than 0.5 PVU (see Figure 12c,d). The ensemble-median exhibits a net diabatic PV gain of around 0.1 PVU for both models with at least some trajectories exhibiting small net diabatic reduction of PV along the trajectories, as shown by the 25th percentile of $\triangle \mathrm{PV}$ in Table 1 . The WCB2 parcels also experience significant warming but of slightly lesser amplitude than in WCB1 (compare Figure 13a,b to Figure 12a,b). The difference between models is smaller for this branch with an ensemble-median difference of only around $1 \mathrm{~K}$ (see Table 1). Furthermore, the PV values of WCB2 parcels located close to the core of the low are much higher $(\mathrm{PV}>1.5 \mathrm{PVU})$ than those of the parcels in WCB1 (compare Figure 13c,d to Figure 12c,d). In this case, both models agree in that there is an enhancement of PV but they disagree in the magnitude of the gain: an interquartile range of 0.118 PVU to 2.60 PVU for the MetUM but only 0.043 PVU to 0.75 PVU for the COSMO model.

Figure 14 shows the total rate of change in PV in the MetUM and the COSMO model along WCB1 and WCB2. The total PV generation rates in both models are consistent with the DHRs obtained. In the MetUM there is gain of PV in WCB1 in the median at low levels, changing sign around $800 \mathrm{hPa}$ (Figure 14a, black lines). The crossing of the horizontal axis corresponds to the maximum in total heating (see Figure 9). From this level upwards the median remains close to zero. Every trajectory in the band between the 25th and 75th percentiles experiences a gain in PV below $880 \mathrm{hPa}$. From that point upwards more and more trajectories in that band experience a loss in $\mathrm{PV}$ so that around $830 \mathrm{hPa}$ there are more trajectories losing $\mathrm{PV}$ than 
gaining it. The intensity of the PV sink then decreases until loss and gain become negligible from $450 \mathrm{hPa}$ upwards. The PV rate in WCB2 in the MetUM exhibits similar behaviour but with lower intensity than in WCB1. At low levels the median is positive, crossing the horizontal axis around $820 \mathrm{hPa}$ to coincide with the peak in median total DHR. From that point upwards the median remains very close to zero although there appears to be a gain at upper level. This upper-level positive PV rate is consistent with the reported enhanced PV values (Figure 13(c)) and net diabatic PV gain (Table 1) in WCB2, and shows that this gain occurs at upper-levels possibly as a result of other diabatic processes such as radiation.

Figure 14b shows the rate of change in PV due to all (albeit only) microphysical processes along the WCB trajectories in the COSMO model. DPVR in WCB1 crosses from positive to negative at a lower level than the MetUM consistent with a lower maximum in heating. However, it is important to remember that the DPVR method implemented in the COSMO model only accounts for heating associated with microphysical processes and does not include turbulent mixing, radiation or frictional effects. The positive DPVR below $\sim 900 \mathrm{hPa}$ is mainly caused by condensation, but the evaporation of rain and convection contribute also (not shown). When the air parcels further ascend the DPVR becomes negative, as the air parcels are located above the maximum of the DHR and PV starts to decrease. The shape of the total DPVR is dominated by the influence of the condensational heating whereas the other microphysical processes play only minor roles. Around $\sim 700 \mathrm{hPa}$ the heating due to depositional growth of snow leads to a small positive DPVR and partly offsets the negative DPVR associated with decreasing condensation at this height. Consistent with the location of the median DHR maximum in WCB2, the region of positive median DPVR in WCB2 extends higher up than in WCB1. The median crosses the horizontal axis around $880 \mathrm{hPa}$ and becomes negative but small, remaining around zero beyond that point.

\section{Summary and conclusions}

A detailed case study analysis of WCB flows, and the processes contributing to diabatic heating and potential vorticity modification within them, has been presented. Diagnostics from two models, the MetUM and the COSMO model, were used to characterise the WCB and to evaluate diabatic heating and PV modification. It is shown that the two models are able to represent 
the split of the WCB in a consistent manner. In both models the trajectories in WCB1 ascend further south and have higher specific humidity than those in WCB2. The WCB1 trajectories ascend abruptly in narrow regions of intense ascent along the cold front south of the cyclone, whereas those in WCB2 experience slower saturated ascent close to the cyclone centre where the WCB flows over the warm front. WCB1 trajectories reach higher isentropes than WCB2 trajectories, where they are carried by the prevailing winds in the upper-level jet and hence curve anticyclonically. One of the main differences between branches is the net change in $\theta$, which is larger for WCB1 than for WCB2. This difference determines the final isentropic level of the parcels which influences whether they will turn anticyclonically into the upper-level ridge or cyclonically to wrap around the cyclone centre. It has also been shown that WCB1 exhibits lower PV values than WCB2 at their respective outflows. The low-PV outflow from WCB1 may enhance the amplification of the developing Rossby wave. The enhancement of PV in the outflow in WCB2 is the result of positive PV rates at upper levels and therefore is likely to occur due to the influence of non-conservative processes such as mixing and radiative transfer.

The paradigm of a WCB that splits into cyclonic and anticyclonic branches dates back to Young et al. (1987) (although references to a split of an ascending warm-sector airflow can be traced back to Namias (1939)). Using trajectory calculations, Wernli (1997) described the characteristics of two WCB branches (referred to as "coherent ensembles of trajectories") that are similar to the ones identified here (i.e. the trajectory ensemble starting at lower latitudes is initially moister, reaches higher isentropes and turns mainly anticyclonically at upper levels). Here, the cyclonic and anticyclonic conveyor belt branches were discriminated by the potential temperature at the end of 48-hour trajectories, ascending at least $600 \mathrm{hPa}$, calculated using the resolved winds. The WCB structure is broadly consistent with that diagnosed through isentropic analysis by Browning and Roberts (1994) - a lower branch turning cyclonically on lower isentropic surfaces than those of an anticyclonic-turning upper branch. However, trajectory analysis has revealed that the ascent in these branches takes place in different regions in the cyclone and has different contributions from convection.

A split WCB has been analysed in an idealised cyclone using trajectories by Schemm et al. (2013) (their downstream cyclone). However, the behaviour of the two branches in their study contrasts with the results of this case study in terms of their latitude of origin and primary 
ascent locations. Schemm et al. (2013) diagnose a "forward-sloping" (anticyclonically-turning) WCB that originates further north than a "rearward-sloping" (cyclonically-turning) WCB. The anticyclonically-turning WCB ascends very rapidly in the region of the bent-back front whereas the cyclonically-turning WCB ascends more gradually at the surface cold front. These WCB branches also contrast with the results of our case study in that the cyclonically-turning branch ascends to the higher isentropic level (by about $3 \mathrm{~K}$ ), although (as in our case study) the final pressure level is very similar for the two branches. It must be mentioned here that in these idealized studies, latent heating due to cloud formation only consists of a saturation adjustment and that the boundary layer, radiation, microphysics and moist convection schemes are switched off; this may account for some of the differences compared to our case study.

A decomposition of the diabatic heating and PV modification along the trajectories has been diagnosed in both models but through different techniques: tracers that track changes in $\theta$ and moisture variables in the MetUM and the direct calculation of DHRs and the associated rates of diabatic PV in the COSMO model. The MetUM diagnostic has the advantage that the contributions from all the different parameterisation schemes that modify $\theta$, moisture and PV can be diagnosed (and hence their budgets can be balanced) but the disadvantage that it does not provide the detail on the microphysical conversion processes provided by the COSMO diagnostics. In contrast, the COSMO diagnostic provides the contributions that modify $\theta$ and PV only from the dominant large-scale cloud microphysical and convective schemes.

Total DHRs are comparable in the two models for both WCB1 and WCB2 (being larger for WCB1) and both models agree that microphysical processes in the large-scale cloud scheme are the major contributor to this heating; however, the models differ in their assessment of the relative contributions from the convection parameterisation and cloud microphysics schemes. In the COSMO model the contribution from the convection scheme along the median trajectory is much smaller than from the cloud microphysics scheme, whereas in the MetUM it is about half that of the microphysics scheme. This difference arises from a different partitioning between resolved and parameterised convection in these models. If both models are run using the Cain-Fritsch convection scheme they obtain a similar partition. Therefore, we attribute the differences primarily to their different default convection schemes. The WCB1 flow is subject to line convection, forced by strong ascent along the cold front. The WCB2 flow is subject to 
large-scale ascent as the moist isentropic surfaces slope over the warm front. In all the model experiments, the net increase in $\theta$ along a WCB is similar irrespective of the split between parameterised convection and resolved ascent.

The microphysical contributions to diabatic heating found in WCB1 agree closely with those found for the WCB in a different case by Joos and Wernli (2012). Comparison of Figure 11 here to Figure 10b in that paper reveals similar functions for the total heating due to microphysical processes as a function of pressure along the trajectories. In both cases heating from condensation of water vapour dominates at low levels whereas the heating from the depositional growth of ice phase species dominate above the freezing level (both snow and ice in this case but just snow in the case of Joos and Wernli (2012)). The consistency of these two cases (and another case study discussed very briefly in Joos and Wernli (2012)) suggests that these aspects of the microphysical contributions are somewhat generic in cold-season WCBs, at least within the COSMO model.

The net increase in potential temperature between models is robust, including a greater ascent for WCB1 relative to WCB2. Similarly, the net PV change in WCB1 is near zero and slightly positive for both models (Table 1). WCB2 trajectories experience a slight increase in PV associated with microphysical processes in COSMO - the larger PV increase in the MetUM is not just associated with latent heating, but has contributions from surface fluxes, turbulent mixing and radiative transfer. These results are consistent with the analysis of Methven (2013) who argues that the mass-weighted average PV of the outflow of a WCB must equal the average PV of the inflow before ascent and heating has commenced. In other words the net PV change following the WCB should be approximately zero. The argument uses two control volumes that are confined within layers in isentropic coordinates encompassing the WCB inflow and outflow. The volumes follow the horizontal (adiabatic) flow within each layer but mass can be transported diabatically between them as a result of heating. The two fundamental conditions for this to hold are: 1) all the mass transported diabatically from the inflow layer ends up in the outflow layer, and 2) the volumes encompassing the inflow and outflow have the same average PV at the mid-time when half the mass has been transported diabatically between them. The zero PV change is a result of the PV impermeability theorem of (Haynes and McIntyre, 1987) combined with Kelvin's circulation theorem. It does not depend on the details of the 
heating rates or diabatic path between inflow and outflow volumes, including whether or not the vertical motion is resolved or parameterised. Although the theory is consistent with the results presented for this case study, earlier studies (Pomroy and Thorpe, 2000; Joos and Wernli, 2012) have typically indicated a net decrease in PV, such that the outflow at final time has lower PV than the inflow at initial time. This may relate to the fact that the trajectory ensembles were already experiencing ascent at the "initial time" of those calculations and therefore PV had already increased as a result of diabatic mass transport upwards. Also, heating in the boundary layer is found to be important to diabatic PV in the MetUM simulations (Chagnon et al., 2013) and so the conditions of Methven (2013) that the inflow control volume extends below the heating may not be satisfied for the trajectory ensembles in the earlier studies. Figure 7 shows that in this study the mean altitude of the trajectory ensembles was very near the ocean surface. The insensitivity of net PV change to the details of diabatic transport may explain the robustness of the results between models and insensitivity to parameterised convection. However, the net $\theta$-increase within the WCBs determines the level of the outflow layer and this is the integrated effect of all diabatic processes. The value of $\Delta \theta$ is itself strongly constrained by $-L q_{s a t}(0)$ where $q_{s a t}(0)$ is the saturation specific humidity of the inflow because the specific humidity of the outflow must always be so much lower if the WCB reaches the upper troposphere (i.e., almost all the water vapour condenses).

The overriding impression on comparison of the WCB structure in the two models is of similarity, which likely contributes to the close agreement in the Rossby wave structure in the 60-hour forecasts between the two models and to the ECMWF analysis. However, differences in the Rossby wave structure do exist (see Figure 5) and may be attributable to differences in the WCBs. In particular the ridge has greater extent as it wraps around the north of the surface cyclone in the MetUM compared to the COSMO model forecast. This is consistent with the more vigorous WCB1 flow in the MetUM with larger DHRs and larger net increases in potential temperature along trajectories. Although the absolute value of PV in the outflow may be insensitive to the net diabatic transport, diabatic processes determine the level of the WCB outflow in isentropic coordinates, relative to the tropopause, and its spatial extent, which would both influence the flow associated with the negative PV anomaly and the subsequent Rossby wave evolution. 
Systematic forecast errors have been shown to develop in Rossby wave amplitude in regions consistent with the location of the WCB (Dirren et al., 2003; Davies and Didone, 2013). Rodwell et al. (2013) has shown that the worst forecast busts for central Europe can be traced back to misrepresentation of convective weather systems over the eastern USA 6 days earlier. The dynamical link is via latent heat release, diabatic transport of mass to the tropopause level and Rossby wave propagation. Our findings are consistent with the hypothesis that errors in the representation of diabatic processes in WCBs could contribute to such forecast errors, although the results may not be especially sensitive to the details. A criterion for the choice of the case analysed here was that it verified well in forecasts from both models so that the WCB structure could be analysed. In future it would be instructive to identify systematic contributions to forecast error from separate diabatic processes, acting to enhance errors associated with initial condition uncertainty and chaotic model trajectories.

\section{Acknowledgements}

MB acknowledges funding from the Swiss National Science Foundation (Project 200021-130079). The contributions of the Reading authors have been funded by the Natural Environment Research Council (NERC) as part of the DIAMET project, grant number NE/I005196/1. The authors thank the Met Office for making available the Unified Model, and NCAS (National Centre for Atmospheric Sciences) CMS (Computational Modelling Services) for providing computing and technical support. We thank MeteoSwiss and the ECMWF for granting access to the analysis fields. We also acknowledge NCAS for funding the flight of the FAAM aircraft and Ian Renfrew as PI for the T-NAWDEX Pilot field campaign.

\section{References}

Adamson DS, Belcher SE, Hoskins BJ, Plant RS. 2006. Boundary layer friction in mid-latitude cyclones. Q. J. R. Meteorol. Soc. 132: 101-124.

Ahmadi-Givi F, Craig GC, Plant RS. 2004. The dynamics of a mid-latitude cyclone with very strong latent heat release. Q. J. R. Meteorol. Soc. 130: 295-323. 
Arakawa A, Lamb V. 1977. Computational design of the basic dynamical processes of the UCLA General Circulation Model. Methods Comput. Phys. 17: 173-265.

Bader MJ, Forbes GS, Grant JR, Lilley RBE, Waters AJ. 1995. Images in weather forecasting: A practical guide for interpreting satellite and radar imagery. Cambridge University Press. $523 \mathrm{pp}$.

Boutle IA, Beare RJ, Belcher SE, Brown AR, Plant RS. 2010. The moist boundary layer under a mid-latitude weather system. Bound.-Lay. Meteorol. 134: 367-386.

Bracegirdle TJ, Gray SL. 2009. The dynamics of a polar low assessed using potential vorticity inversion. Q. J. R. Meteorol. Soc. 135: 880-893.

Browning KA. 1971. Radar measurements of air motion near fronts. Weather 26: 320-340.

Browning KA. 1990. Organisation of clouds and precipitation in extratropical cyclones. In: Extratropical Cyclones: The Erik Palmén memorial volume, Newton C, Holopainen EO (eds), Amer. Meteorol. Soc., Boston, USA, pp. 129-154.

Browning KA, Roberts NM. 1994. Structure of a frontal cyclone. Q. J. R. Meteorol. Soc. 120: $1535-1557$.

Carlson TN. 1980. Airflow through midlatitude cyclones and the comma cloud pattern. Mon. Weather Rev. 108: 1498-1509.

Chagnon JM, Gray SL. 2009. Horizontal potential vorticity dipoles on the convective storm scale. Q. J. R. Meteorol. Soc. 135: 1392-1408.

Chagnon JM, Gray SL, Methven J. 2013. Diabatic processes modifying potential vorticity in a North Atlantic cyclone. Q. J. R. Meteorol. Soc. 139: 1270-1282.

Charney JG, Phillips NA. 1953. Numerical integration of the quasi-geostrophic equations for barotropic and simple baroclinic flows. J. Meteor. 10(2): 71-99.

Davies HC, Didone M. 2013. Diagnosis and dynamics of forecast error growth. Mon. Weather Rev. 141: 2483-2501.

Davies T, Cullen MJP, Malcolm AJ, Mawson MH, Staniforth A, White AA, Wood N. 2005. A new dynamical core for the Met Office's global and regional modelling of the atmosphere. $Q$. J. R. Meteorol. Soc. 131: 1759-1782.

Davis CA, Stoelinga MT, Kuo YH. 1993. The integrated effect of condensation in numerical simulations of extratropical cyclogenesis. Mon. Weather Rev. 121: 2309-2330. 
Dirren S, Didone M, Davies HC. 2003. Diagnosis of 'forecast-analysis' differences of a weather prediction system. Geophys. Res. Lett. 30: 2060, doi:10.1029/2003GL017986.

Doms G, Förstner J, Heise E, Herzog HJ, Rashendorfer M, Reinhardt T, Ritter B, Schrodin R, Schulz JP, Vogel G. 2007. A description of the nonhydrostatic regional model LM. Part II: physical parameterization. Technical report, Consortium for Small-Scale Modelling. [Available online at http://www.cosmo-model.org].

Eckhardt S, Stohl A, Wernli H, James P, Forster C, Spichtinger N. 2004. A 15-year climatology of warm conveyor belts. J. Climate 17: 218-237.

Edwards J, Slingo A. 1996. Studies with a flexible new radiation code. Part I: Choosing a configuration for a large-scale model. Q. J. R. Meteorol. Soc. 122: 689-719.

Gray SL. 2006. Mechanisms of midlatitude cross-tropopause transport using a potential vorticity budget approach. J. Geophys. Res. 111(D17113): 14 pp, doi:10.1029/2005JD006259.

Gregory D, Rowntree PR. 1990. A mass flux convection scheme with representation of cloud ensemble characteristics and stability-dependent closure. Mon. Weather Rev. 118: 14831506.

Harrold TW. 1973. Mechanisms influencing distribution of precipitation within baroclinic disturbances. Q. J. R. Meteorol. Soc. 99: 232-251.

Haynes P, McIntyre M. 1987. On the evolution of vorticity and PV in the presence of diabatic heating and frictional or other forces. J. Atmos. Sci. 44: 828-841.

Hobbs PV, Biswas KR. 1979. The cellular structure of narrow cold-frontal rainbands. Q. J. $R$. Meteorol. Soc. 105: 723-727.

Hoskins BJ, McIntyre ME, Robertson AW. 1985. On the use and significance of isentropic potential vorticity maps. Q. J. R. Meteorol. Soc. 111: 877-946.

Joos H, Wernli H. 2012. Influence of microphysical processes on the potential vorticity development in a warm conveyor belt: a case-study with the limited-area model COSMO. Q. J. R. Meteorol. Soc. 138: 407-418.

Kain JS. 2004. The Kain-Fritsch convective parameterization: An update. J. Appl. Meteor. 43: $170-181$.

Kain JS, Fritsch JM. 1990. A one-dimensional entraining/detraining plume model and its application in convective parameterization. J. Atmos. Sci. 47: 2784-2802. 
Knippertz P, Chagnon JM, Foster A, Lathouwers L, Marsham JH, Methven J, Parker DJ. 2010. Research flight observations of a prefrontal gravity wave near the southwestern UK. Weather 65: $293-297$.

Lock AP, Brown AR, Bush MR, Martin GM, Smith RNB. 2000. A new boundary layer mixing scheme. Part I: Scheme description and single-column model tests. Mon. Weather Rev 128: $3187-3199$.

Lorenz E. 1960. Energy and numerical weather prediction. Tellus 12(4): 364-373.

Louis JF. 1979. A parametric model of vertical eddy fluxes in the atmosphere. Bound.-Lay. Meteorol. 17: 187-202.

Martin JE. 1998. The structure and evolution of a continental winter cyclone. Part I: Frontal structure and the occlusion process. Mon. Weather Rev. 126: 303-328.

Martin JE. 1999. Quasigeostrophic forcing of ascent in the occluded sector of cyclones and the trowal airstream. Mon. Weather Rev. 127: 70-88.

Martin JE. 2006. Mid-latitude atmospheric dynamics. Wiley, Chichester. 523pp.

Martínez-Alvarado O, Plant RS. 2013. Parameterised diabatic processes in numerical simulations of an extratropical cyclone. Q. J. R. Meteorol. Soc. In press.

Mellor G, Yamada T. 1982. Development of a turbulence closure model for geophysical fluid problems. Rev. Geophys. Space Phys. 20: 851-875.

Methven J. 2013. Potential vorticity in warm conveyor belt outflow. Q. J. R. Meteorol. Soc. Submitted.

Namias J. 1939. The use of isentropic analysis in short term forecasting. J. Aeronaut. Sci. 6.

Pavan V, Hall N, Valdes P, Blackburn M. 1999. The importance of moisture distribution for the growth and energetics of mid-latitude systems. Ann. Geophys. 17: 241-256.

Plant RS, Belcher SE. 2007. Numerical simulation of baroclinic waves with a parameterized boundary layer. J. Atmos. Sci. 64: 4383-4399.

Pomroy HB, Thorpe AJ. 2000. The evolution and dynamical role of reduced upper-tropospheric potential vorticity in intensive observing period one of fastex. Mon. Weather. Rev. 128: 18171834.

Ritter B, Geleyn JF. 1989. A comprehensive radiation scheme for numerical weather prediction models with potential applications in climate simulations. Mon. Weather Rev. 120: 303-325. 
Rodwell MJ, Magnusson L, Bauer P, Bechtold P, Bonavita M, Cardinali C, Diamantakis M, Earnshaw P, Garcia-Mendez A, Isaksen L, et al. 2013. Characteristics of occasional poor medium-range weather forecasts for europe. B. Am. Meteorol. Soc. Doi: 10.1175/BAMS-D12-00099.1.

Schemm S, Wernli H, Papritz L. 2013. Warm conveyor belts in idealized moist baroclinic wave simulations. J. Atmos. Sci. 70: 627-652.

Schultz DM. 2001. Reexamining the cold conveyor belt. Mon. Weather Rev. 129: 2205-2225.

Schultz DM, Vaughan G. 2011. Occluded fronts and the occlusion process: A fresh look at conventional wisdom. B. Am. Meteorol. Soc. 92: 443-466.

Sinclair VA, Belcher SE, Gray SL. 2010. Synoptic controls on boundary-layer characteristics. Bound.-Lay. Meteorol. 134: 387-409.

Steppeler J, Doms G, Schättler U, Bitzer HW, Gassmann A, Damrath U, Gregoric G. 2003. Meso-gamma scale forecast using the nonhydrostatic model LM. Meteorol. Atmos. Phys. 82: $75-96$.

Stoelinga MT. 1996. A potential vorticity-based study of the role of diabatic heating and friction in a numerically simulated baroclinic cyclone. Mon. Weather Rev. 124: 849-874.

Thorncroft CD, Hoskins BJ, McIntyre ME. 1993. Two paradigms of baroclinic-wave life-cycle behaviour. Q. J. R. Meteorol. Soc. 119: 17-55.

Tiedtke M. 1989. A comprehensive mass flux scheme for cumulus parameterization in large-scale models. Mon. Weather Rev. 117: 1779-1799.

Wernli H. 1997. A Lagrangian-based analysis of extratropical cyclones. II: A detailed case-study. Q. J. R. Meteorol. Soc. 123: 1677-1706.

Wernli H, Davies HC. 1997. A Lagrangian-based analysis of extratropical cyclones. I: The method and some applications. Q. J. R. Meteorol. Soc. 123: 467-489.

Whitaker JS, Davis CA. 1994. Cyclogenesis in a saturated environment. J. Atmos. Sci. 51: 889-907.

Wilson DR, Ballard SP. 1999. A microphysically based precipitation scheme for the UK Meteorological Office Unified Model. Q. J. R. Meteorol. Soc. 125: 1607-1636.

Young MV, Monk GA, Browning KA. 1987. Interpretation of satellite imagery of a rapidly deepening cyclone. Q. J. R. Meteorol. Soc. 113: 1089-1115. 
(a) SURFACE PRESSURE - CROWN COPYRIGHT MET OFFICE

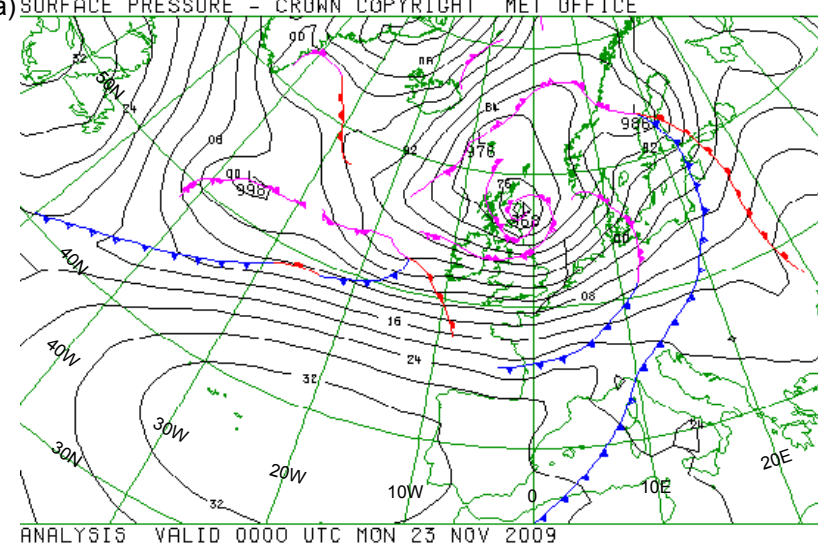

(c) 5
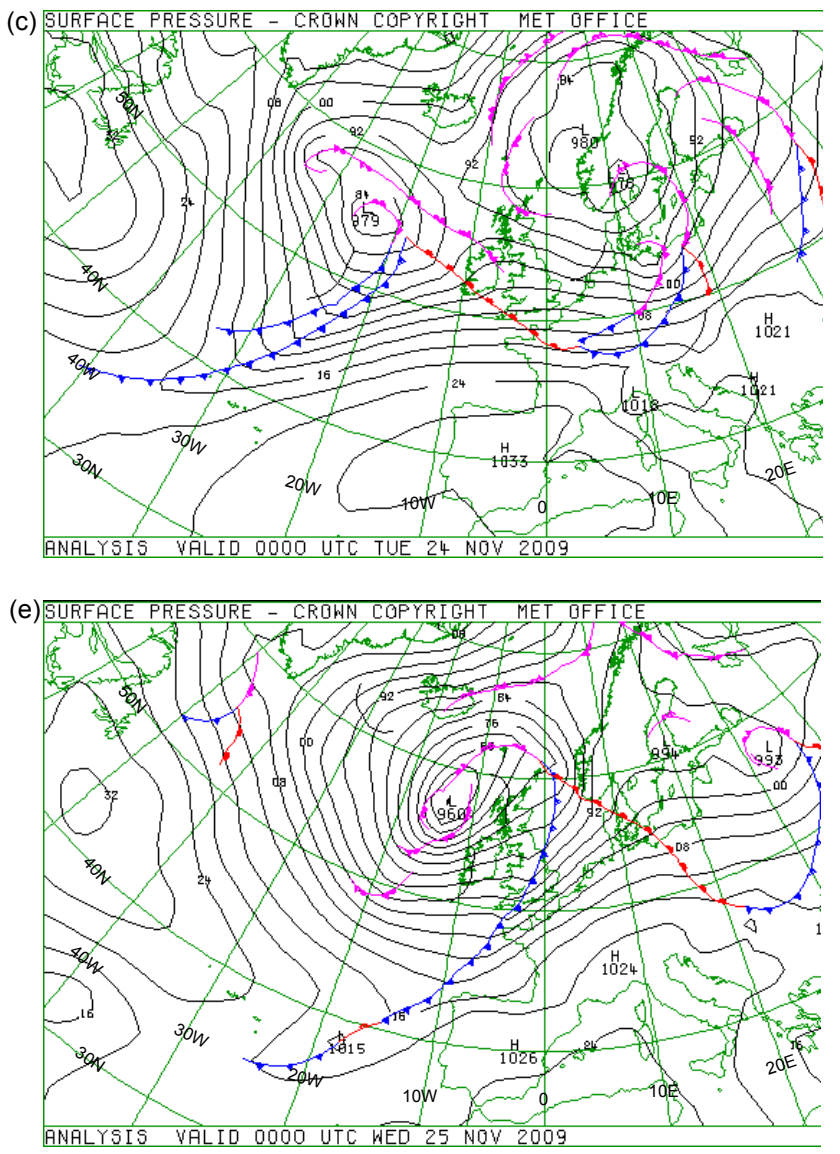

(b) 00 UTC $23 / 11 / 2009$

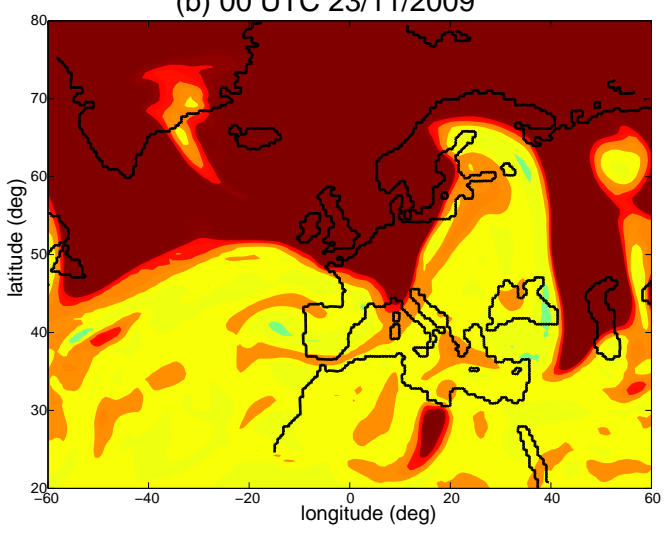

(d) 00 UTC 24/11/2009

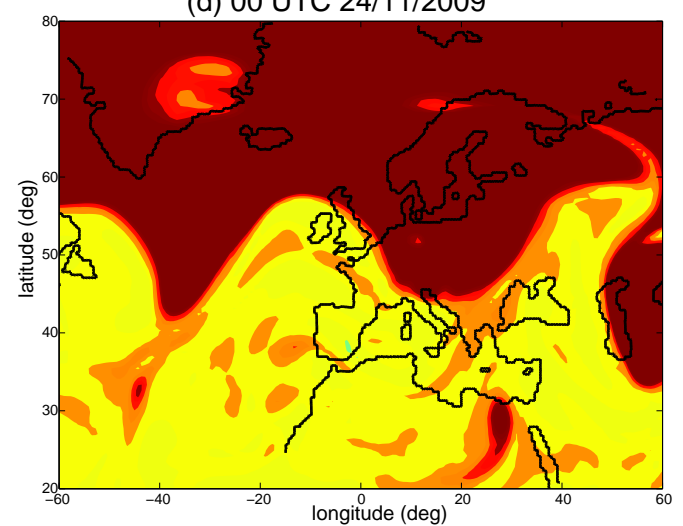

(f) 00 UTC 25/11/2009

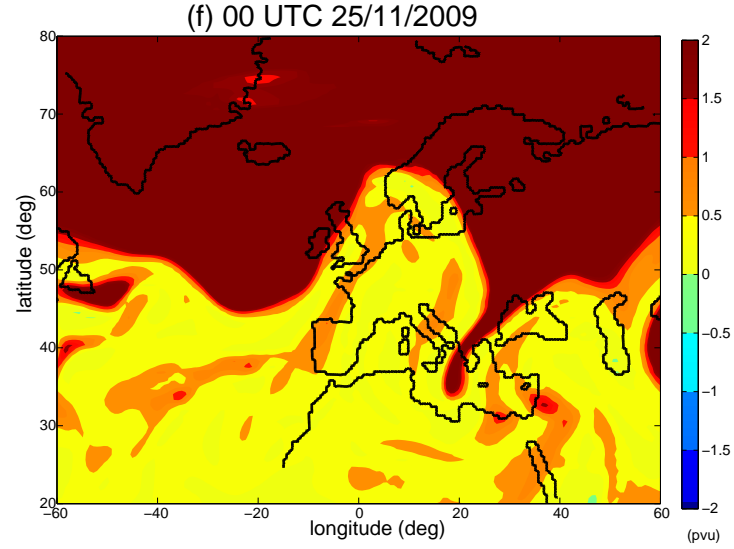

Figure 2: (a,c,e) Met Office surface analyses (c)2009 Crown Copyright, the Met Office) and $(\mathrm{b}, \mathrm{d}, \mathrm{f}) \mathrm{PV}$ on the $315 \mathrm{~K}$ isentropic surface in ECMWF analysis valid at $0000 \mathrm{UTC}$ on $(\mathrm{a}, \mathrm{b}) 23$ November, (c,d) 24 November and (e,f) 25 November 2009. 

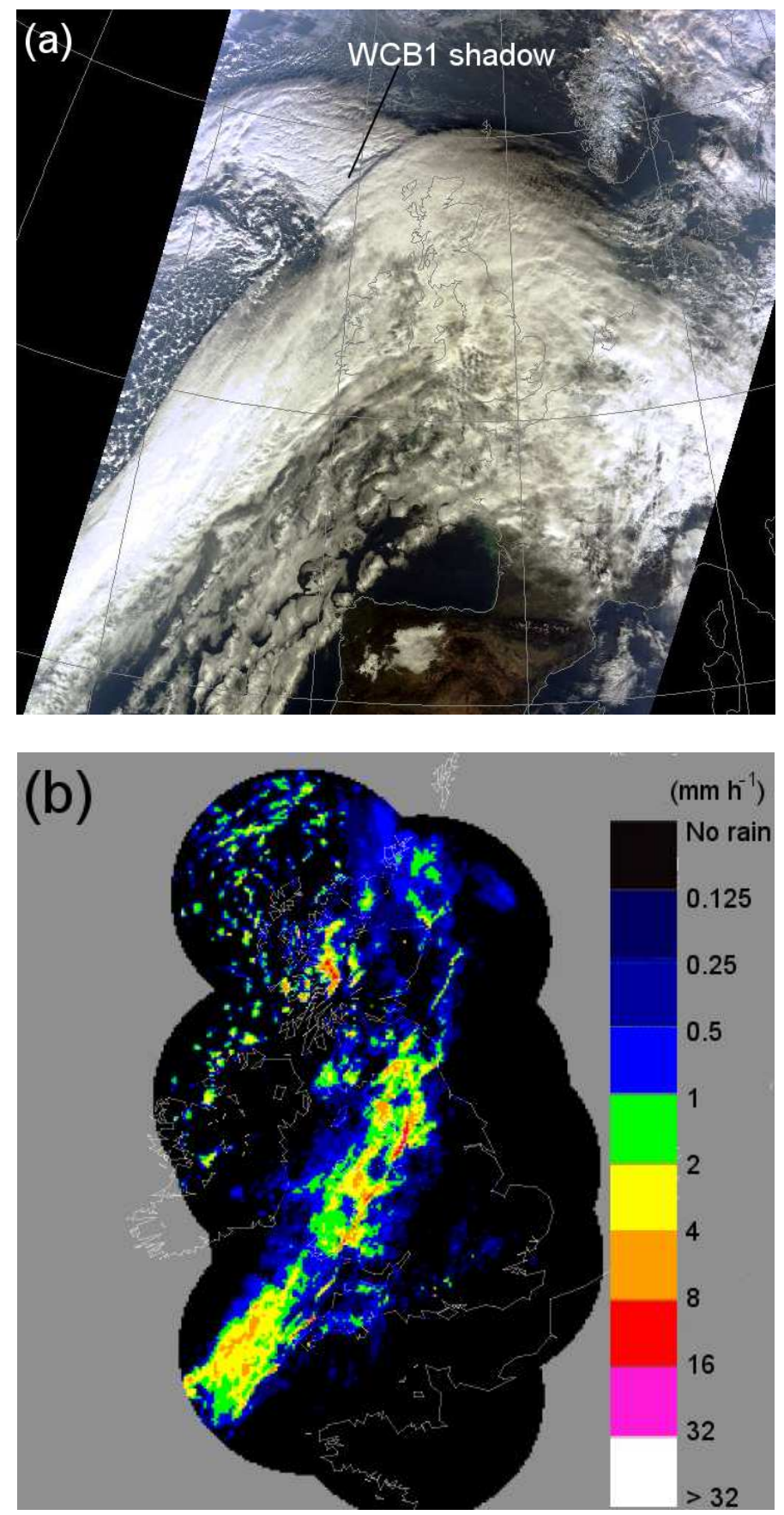

Figure 3: (a) RGB composite satellite image (MODIS channels 1, 3, 4) at 1127 UTC 24 November 2009 (Satellite image courtesy of the NERC Satellite Receiving Station, Dundee University, Scotland, http://www.sat.dundee.ac.uk/), and (b) Met Office radar-derived precipitation rate, valid at 2100 UTC 24 November 2009. 
(a) $\theta_{e}$, Dropsonde Leg

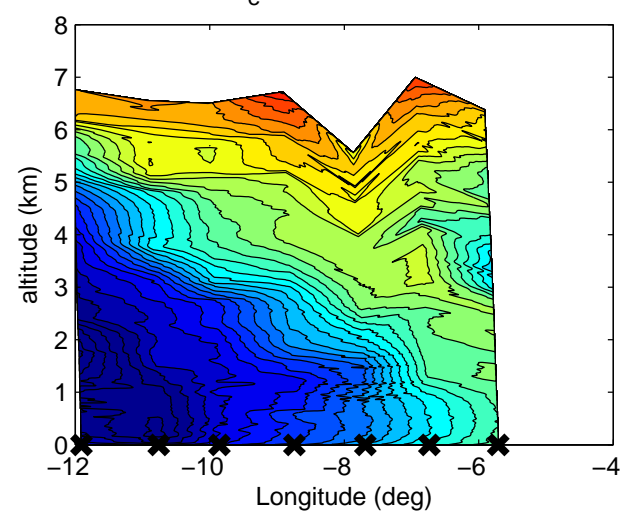

(c) v, Dropsonde Leg

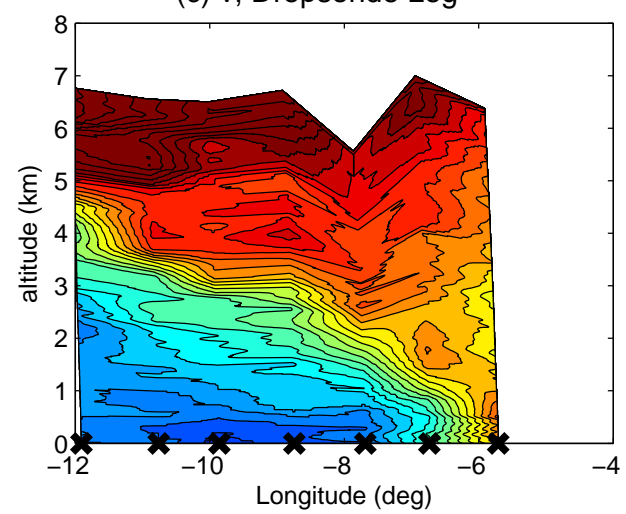

(b) $\theta$, MetUM

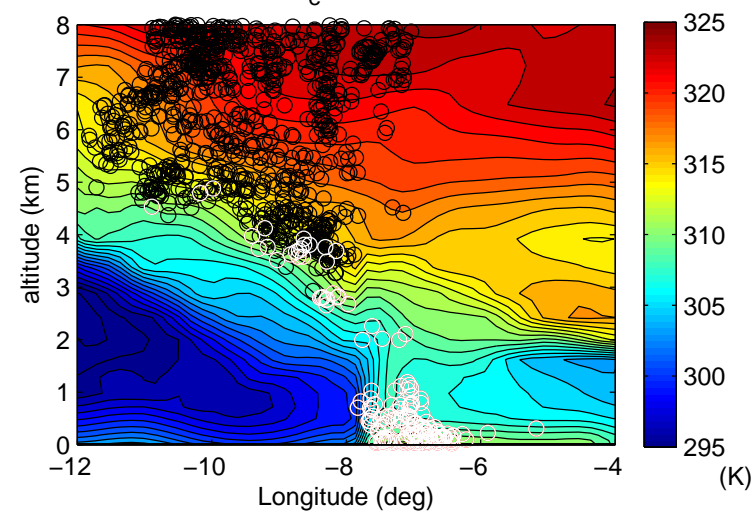

(d) v, MetUM

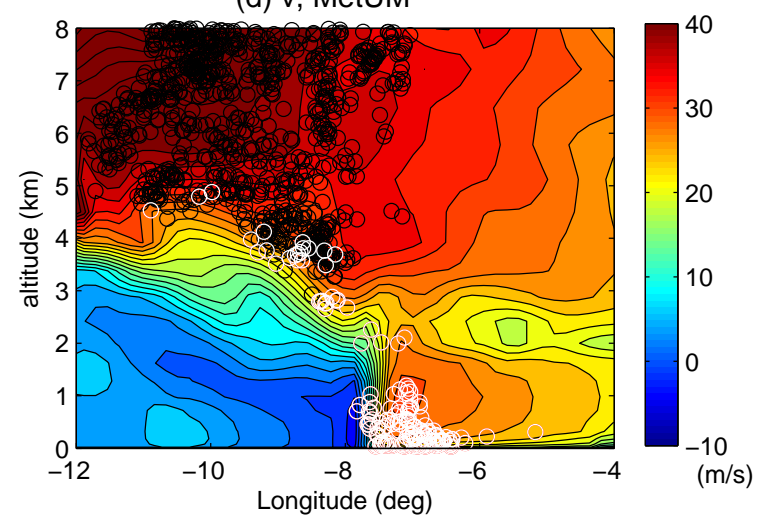

Figure 4: Dropsonde sections across the cold front of (a) equivalent potential temperature and (c) meridional wind component on 24 November between $1700-1800$ UTC at $51^{\circ} \mathrm{N}$. The corresponding sections valid at 1700 UTC 24 November $(\mathrm{T}+35)$ from the MetUM forecast are shown in $(b, d)$. Locations of the WCB trajectories intersecting this section are plotted in the model sections (black circles correspond to WCB1; white circles correspond to WCB2). Crosses in (a) and (c) indicate dropsonde locations. 
(a)

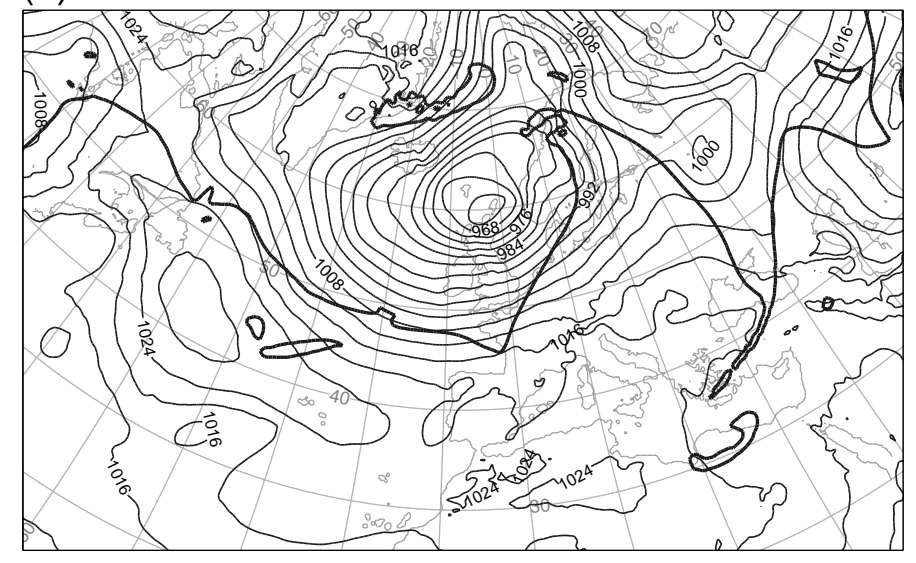

(b)

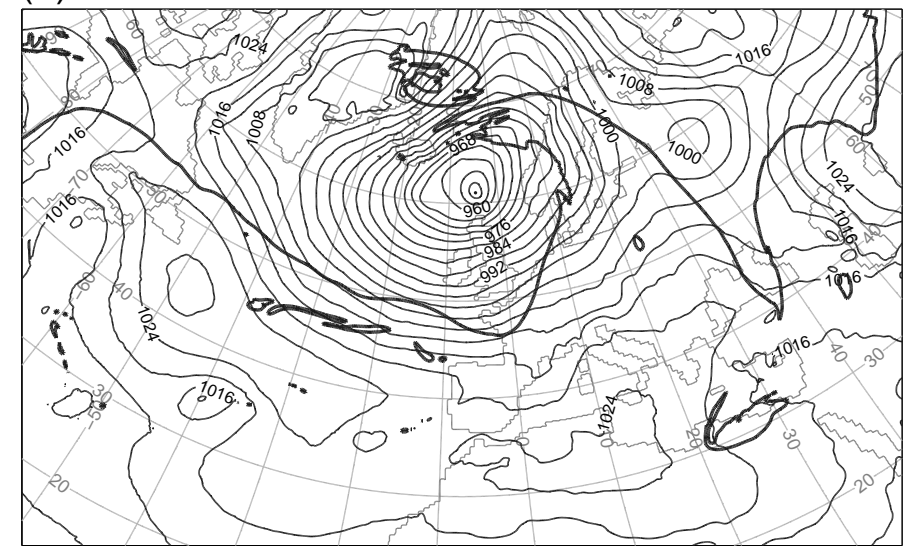

(c)

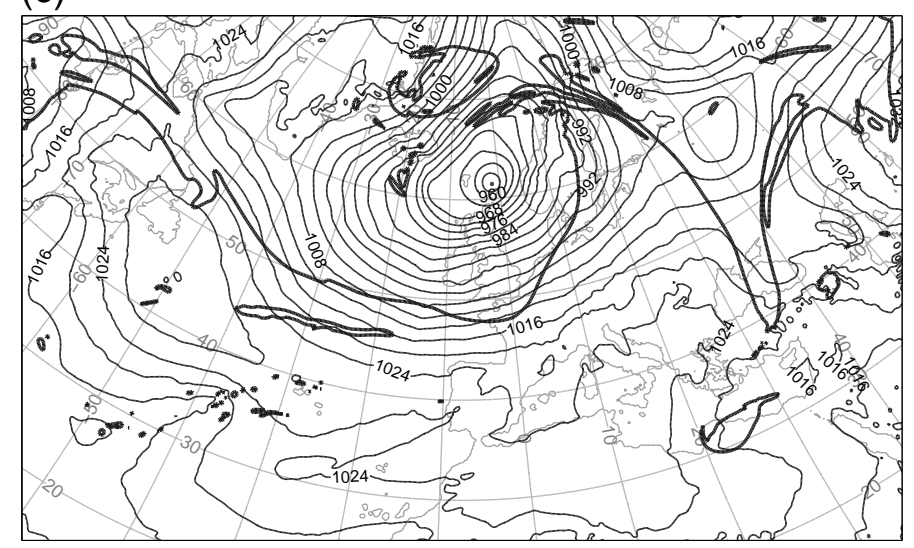

Figure 5: Tropopause trough/ridge structure in (a) the ECMWF operational analysis, (b) the MetUM and (c) the COSMO model, showing the 2-PVU isoline on the 315-K isentropic surface (bold line) and MSLP every $4 \mathrm{hPa}$ (thin lines) at 1800 UTC 25 November 2009 (corresponding to $\mathrm{T}+60$ for MetUM and COSMO model forecasts). 

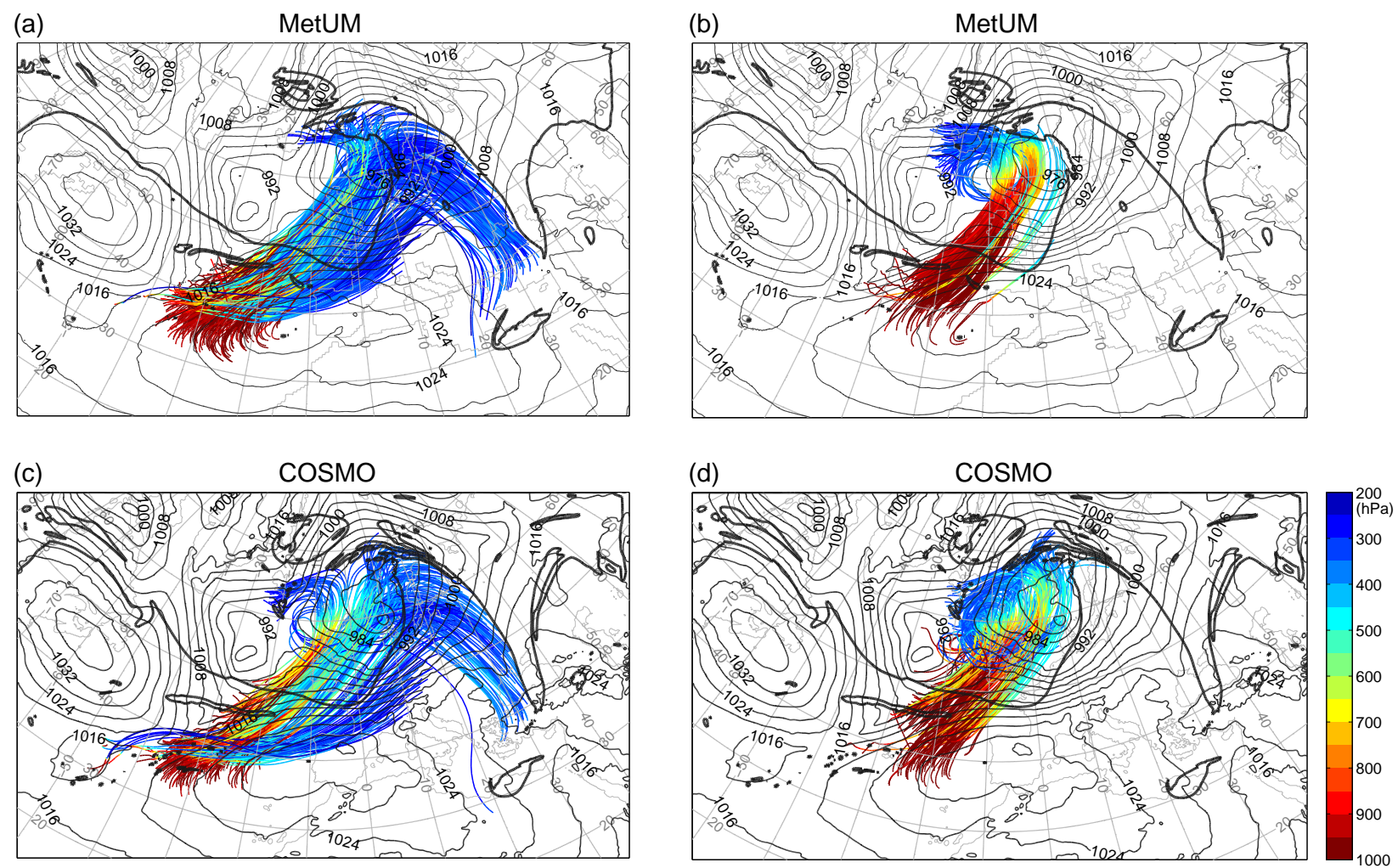

Figure 6: Maps showing the full trajectory ensembles (coloured by pressure, in hPa) in (a,b) the MetUM and (c,d) the COSMO model showing the branches WCB1 (left column) and WCB2 (right column). Also shown are MSLP (isobars every $4 \mathrm{hPa}$ ) at the start of trajectories (1800 UTC 23 November 2009) and 2-PVU isoline on the 315-K isentropic surface at the end of trajectories (1800 UTC 25 November 2009) as output by the corresponding model. 

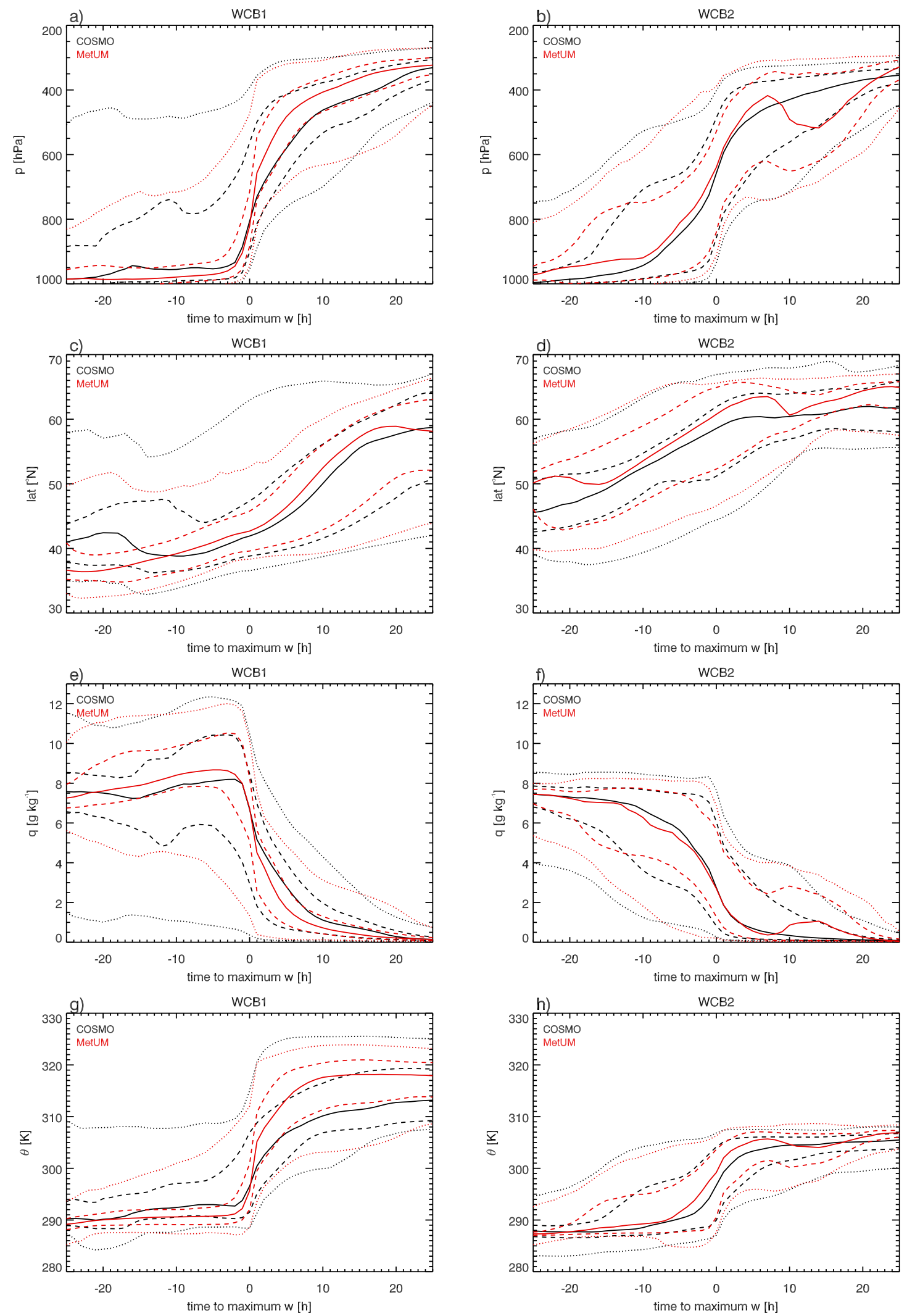

Figure 7: (a,b) Pressure, (c,d) latitude, (e,f) specific humidity and $(\mathrm{g}, \mathrm{h})$ potential temperature along trajectories as a function of time for (a,c,e,g) WCB1 and (b,d,f,h) WCB2 with time zero defined as the time of maximal ascent for the MetUM (red lines) and the COSMO model (black lines). Solid lines represent the ensemble median; dashed lines represent the 25th and 75th percentiles; dotted lines represent the 5th and 95th percentiles. 


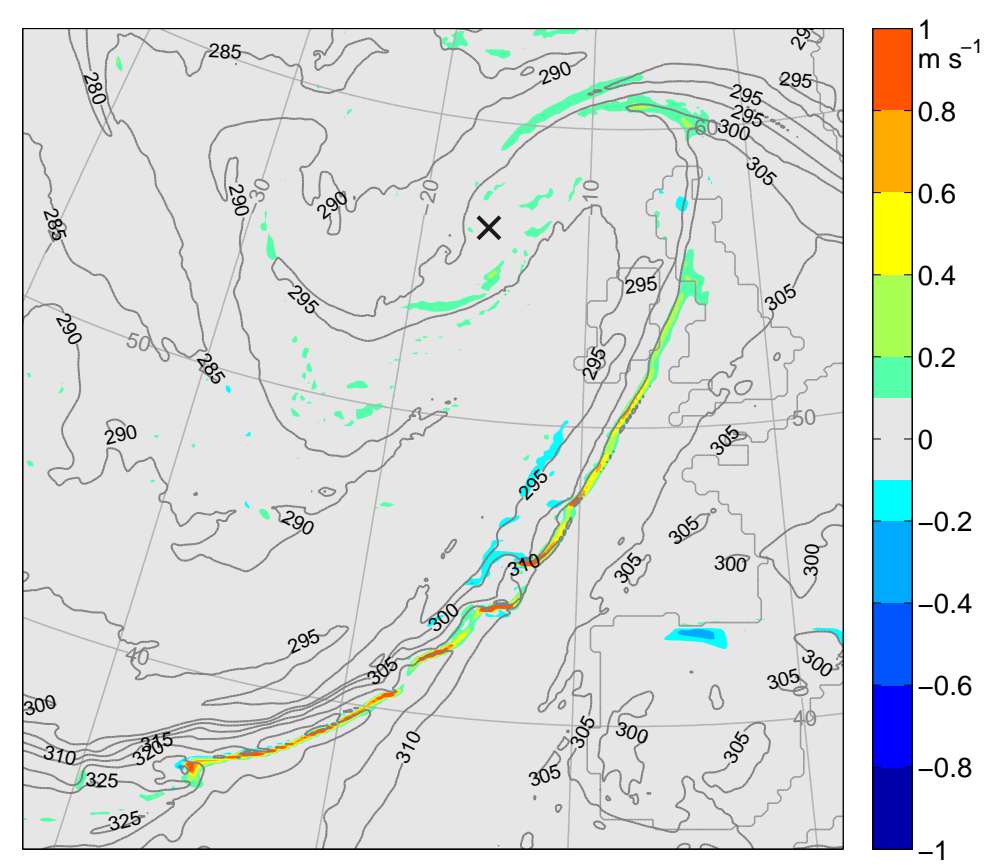

Figure 8: Map of 850-hPa vertical velocity (in $\mathrm{m} \mathrm{s}^{-1}$, filled contours) and $\theta_{e}$ (in $\mathrm{K}$, contoured every 5 K) at 1800 UTC 24 November 2009 from the MetUM.

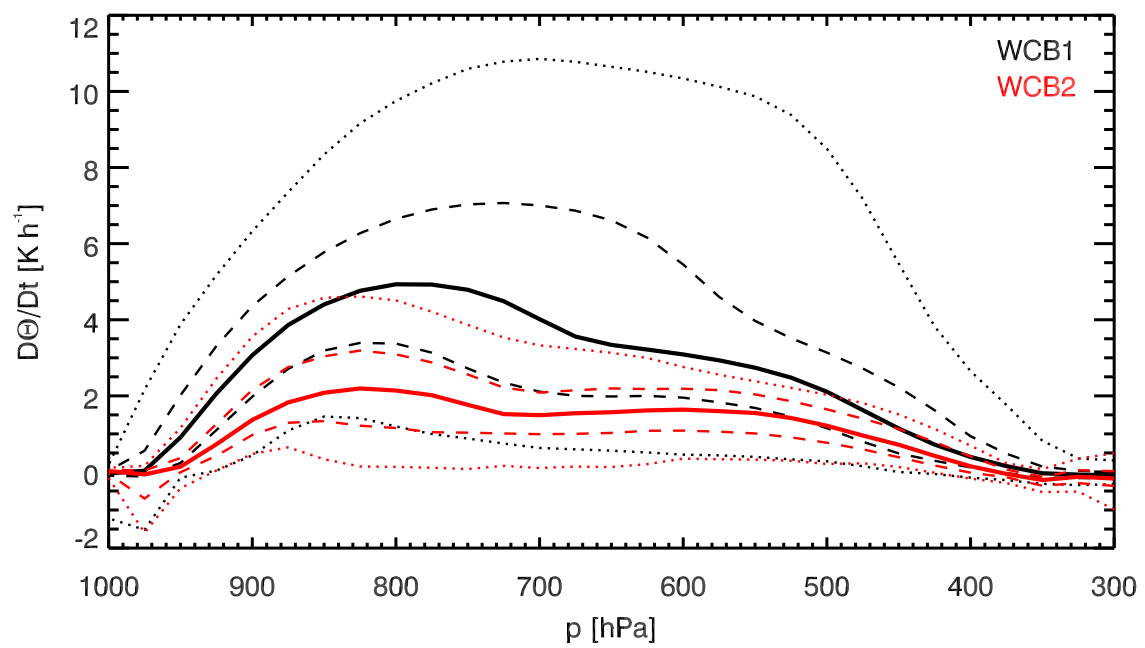

Figure 9: Total DHR as a function of pressure for WCB1 (black) and WCB2 (red) in the MetUM. Solid lines represent ensemble medians; dashed lines represent the 25th and 75th percentiles; dotted lines represent the 5 th and 95 th percentiles. 

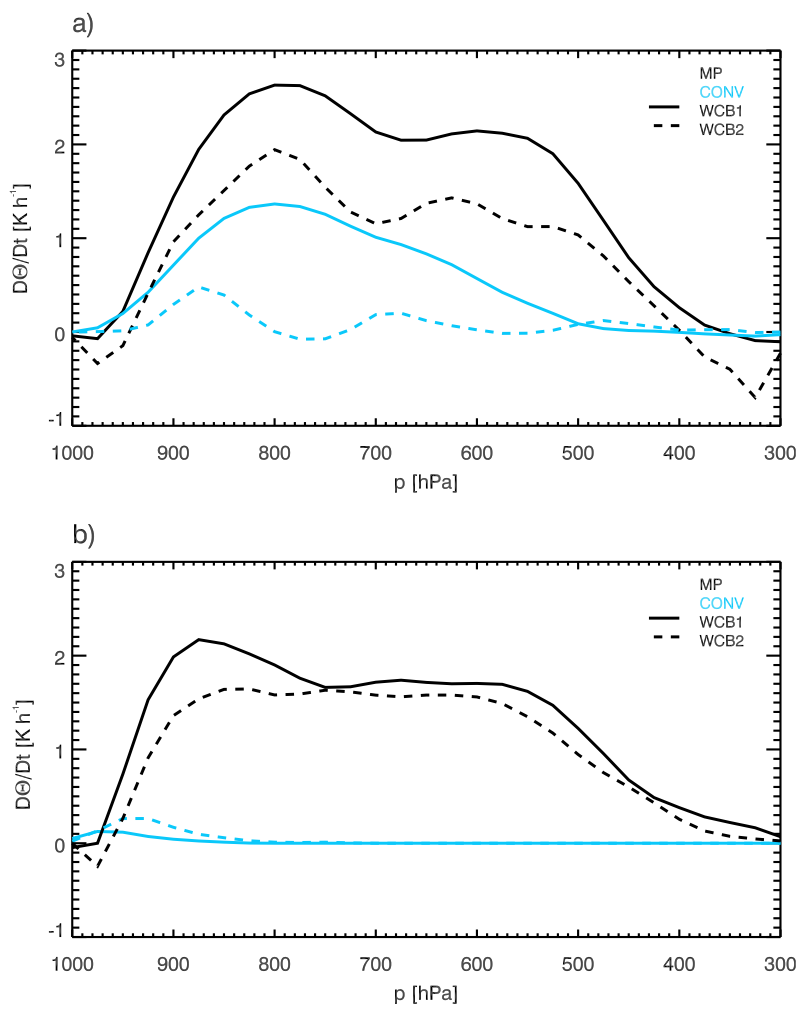

Figure 10: Ensemble-medians of contributions to total DHR due to cloud microphysics (black) and convection (blue) as functions of pressure for WCB1 (solid lines) and WCB2 (dashed lines) in (a) the MetUM and (b) the COSMO model.

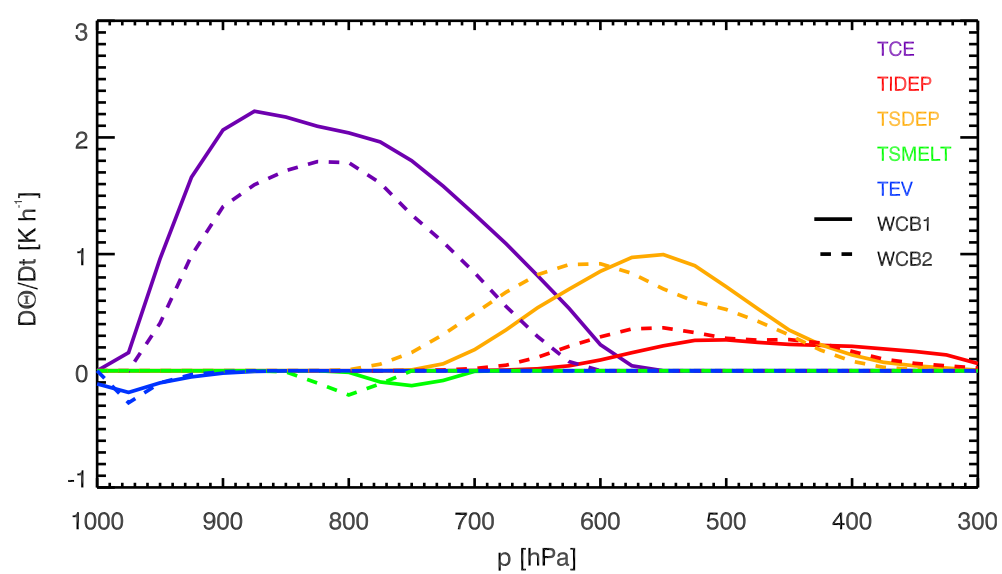

Figure 11: Ensemble-medians of DHR contributions due to condensation/evaporation (TCE), depositional growth of ice (TIDEP), depositional growth of snow (TSDEP), melting of snow (TSMELT) and evaporation of rain (TEV) as functions of pressure for WCB1 (solid lines) and WCB2 (dashed lines) in the COSMO model. 

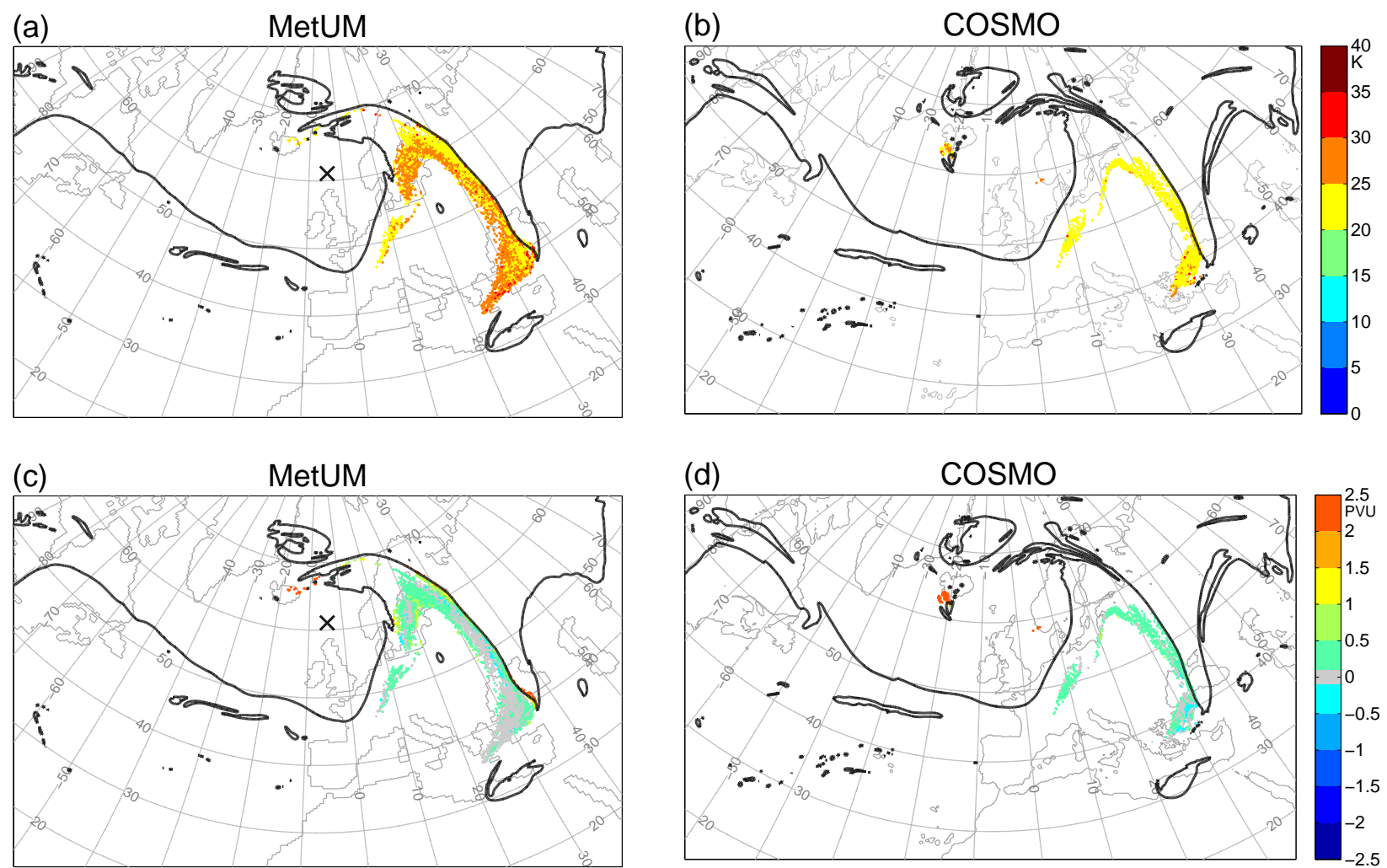

Figure 12: 2-PVU isoline on the 315-K isentropic surface at 1800 UTC 25 November 2009 in $(\mathrm{a}, \mathrm{c})$ the MetUM and $(\mathrm{b}, \mathrm{d})$ the COSMO model showing intersecting WCB1 parcels coloured by $(\mathrm{a}, \mathrm{b}) \Delta \theta$ (in 48 hours), in $\mathrm{K}$, and $(\mathrm{c}, \mathrm{d}) \mathrm{PV}$, in PVU.

(a)

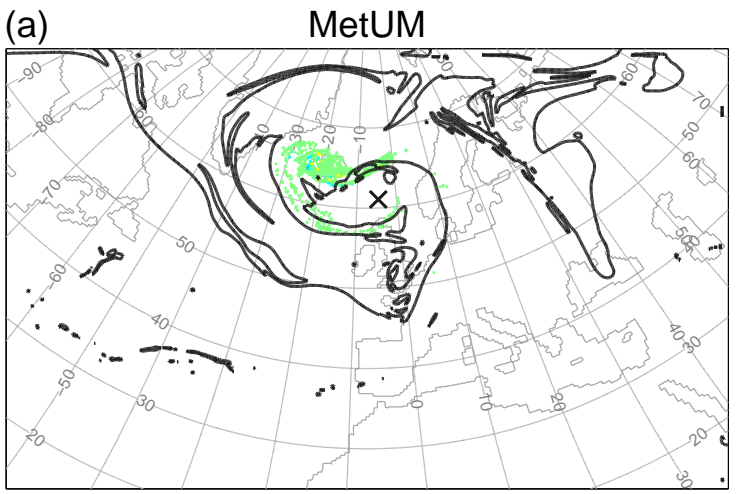

(c)

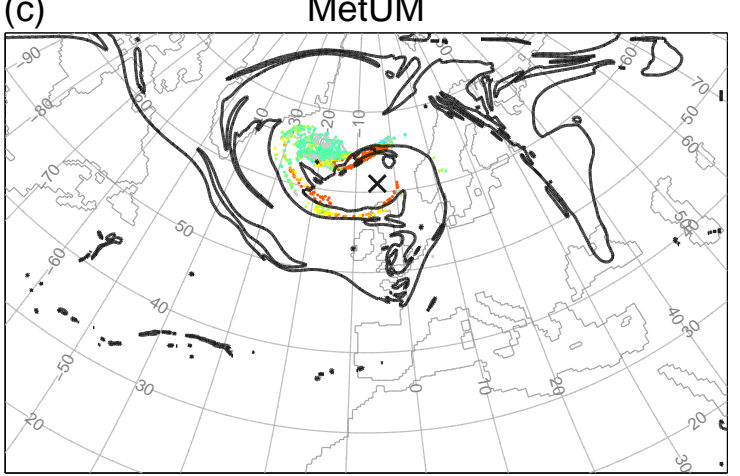

(b)

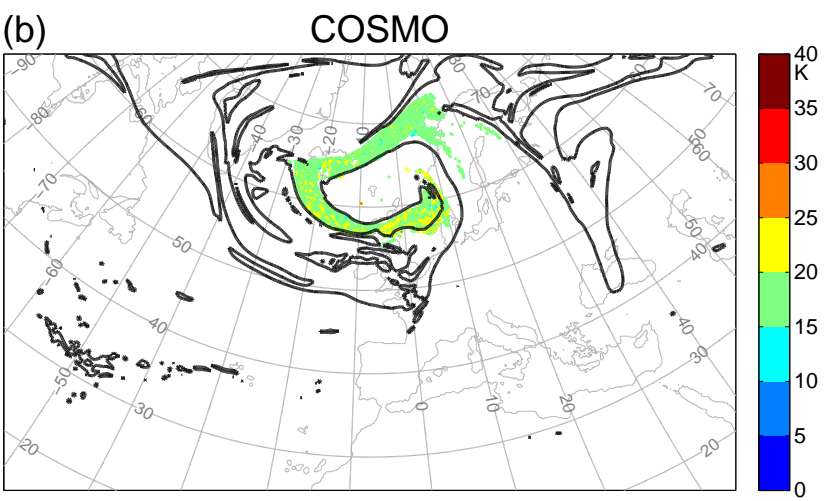

(d)

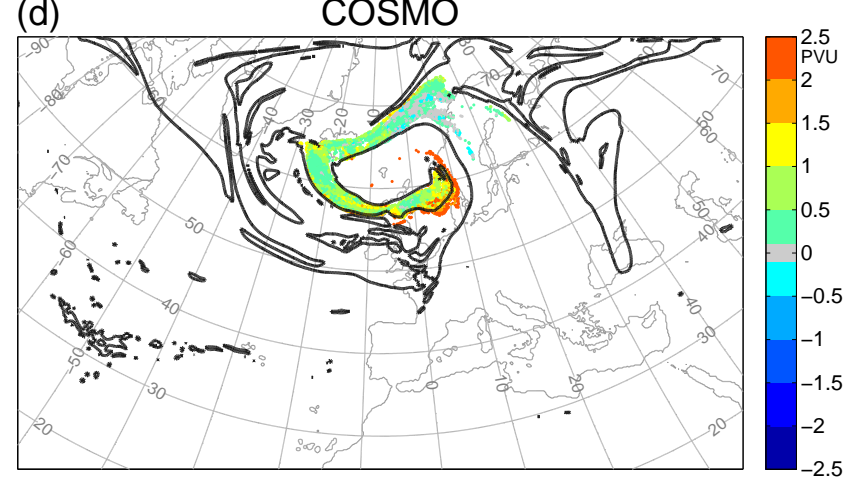

Figure 13: As in Figure 13 but for the 305-K isentropic surface and WCB2 parcels. 

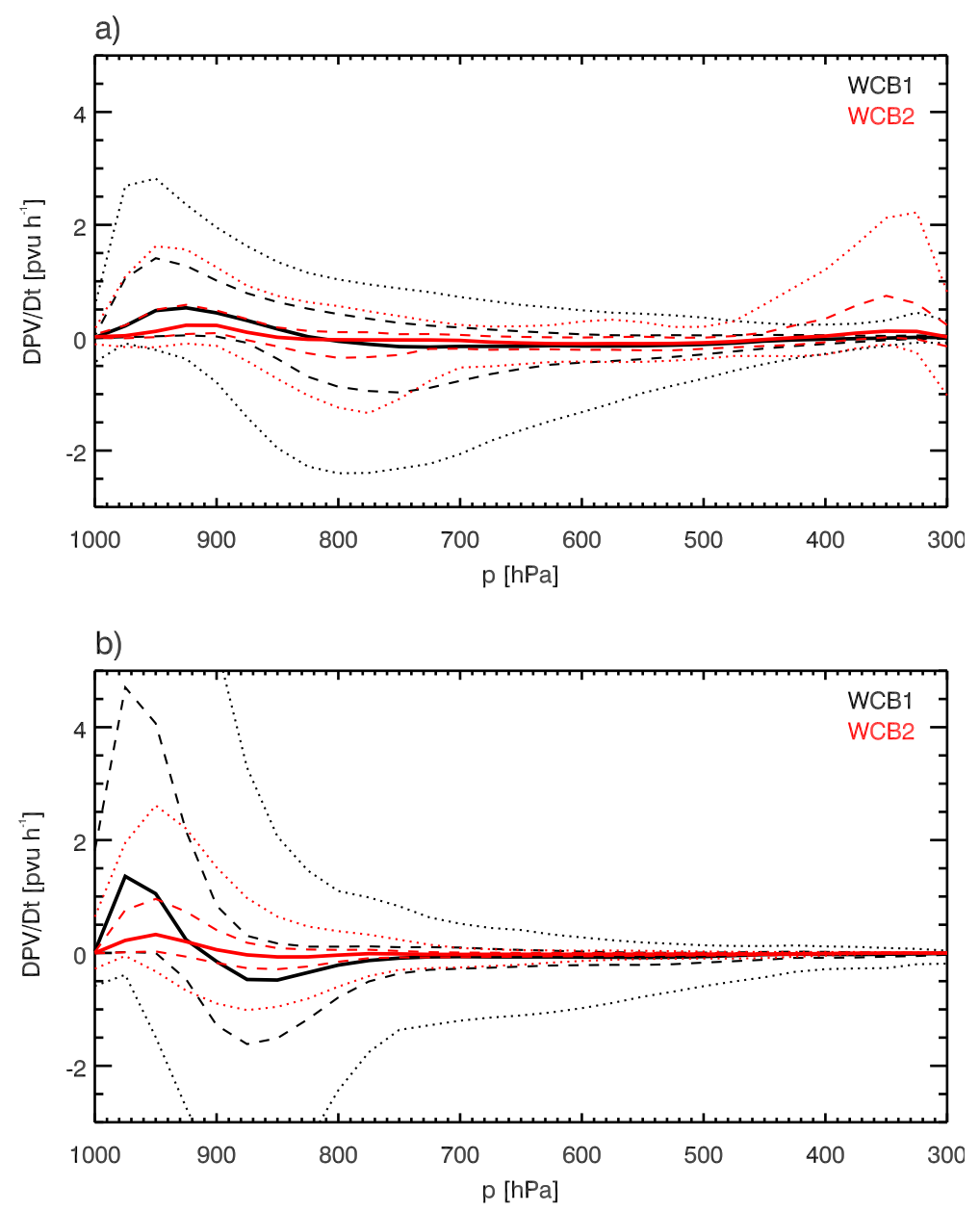

Figure 14: PV rates of change as functions of pressure for WCB1 (black) and WCB2 (red) for (a) the MetUM and (b) the COSMO model. Solid line represents the ensemble median; dashed lines represent the 25th and 75th percentiles; dotted lines represent the 5th and 95th percentiles. 